Board of Governors of the Federal Reserve System

International Finance Discussion Papers

Number 627

October 1998

\title{
TRADEOFFS BETWEEN INFLATION AND OUTPUT-GAP VARIANCES IN AN OPTIMIZING-AGENT MODEL
}

Christopher J. Erceg, Dale W. Henderson, Andrew T. Levin

NOTE: International Finance Discussion Papers are preliminary materials circulated to stimulate discussion and critical comment. References in publications to International Finance Discussion Papers (other than an acknowledgment that the writer has had access to unpublished material) should be cleared with the author or authors. Recent IFDPs are available on the Web at www.bog.frb.fed.us. 


\title{
TRADEOFFS BETWEEN INFLATION AND OUTPUT-GAP VARIANCES IN AN OPTIMIZING-AGENT MODEL
}

\author{
Christopher J. Erceg, Dale W. Henderson, Andrew T. Levin*
}

\begin{abstract}
We demonstrate the existence of a monetary policy tradeoff between price-inflation variability and output-gap variability in an optimizing-agent model with staggered nominal wage and price contracts. This variance tradeoff is absent only in the special case in which prices are sticky and wages are perfectly flexible. When the model is calibrated to exhibit an empirically reasonable degree of nominal wage inertia, strict inflation targeting induces substantial output-gap volatility.
\end{abstract}

Keywords: monetary policy frontier, inflation targeting, sticky wages, sticky prices, staggered contracts, determinacy.

\footnotetext{
* All three authors are economists in the International Finance Division of the Federal Reserve Board. Earlier versions were presented at the Federal Reserve Board, the Swedish National Bank - Institute for International Economic Studies (IIES) Conference on Monetary Policy Rules, the meetings of the Western Economic Association, and the Federal Reserve Bank of Chicago. The authors would like to thank Stefan Gerlach, their discussant at the Swedish National Bank -IIES Conference, for helpful comments; John Taylor and Michael Woodford for useful discussions; and Carolina Marquez for valuable research assistance. The views in this paper are solely the responsibility of the authors and should not be interpreted as reflecting the views of the Board of Governors of the Federal Reserve System or of any other person associated with the Federal Reserve System. The email addresses of the authors are ercegc@frb.gov, hendersd@frb.gov, and levina@frb.gov, respectively.
} 


\section{Introduction}

For at least two decades, economists have investigated the monetary policy tradeoff between price inflation variability and output gap variability, using a wide variety of theoretical and empirical models. ${ }^{1}$ However, the existence of a variance tradeoff has been called into question in recent analysis of dynamic general equilibrium models with optimizing agents, staggered price setting, and completely flexible wages; in these models, monetary policy rules that keep the inflation rate constant also minimize output gap variability. ${ }^{2}$ Thus, it is important to determine whether the absence of an output-inflation variance tradeoff is a general implication of models with optimizing agents or a specialized result due to particular assumptions about the form of nominal inertia. $^{3}$

In this paper, we analyze a dynamic general equilibrium model with optimizing agents, in which both wages and prices are determined by staggered nominal contracts. ${ }^{4}$ When nominal wages are sticky, we demonstrate the existence of a variance tradeoff between price inflation and the output gap, regardless of the degree of price stickiness. In fact, the variance tradeoff is absent only in the special case where prices are sticky and wages are completely flexible. When the model is calibrated to exhibit an empirically reasonable degree of nominal inertia, strict price inflation targeting induces substantial output-gap volatility. Furthermore, the variance tradeoff is relatively flat, so that output gap variability can be drastically reduced without inducing much variation in price inflation.

Even in the absence of nominal wage inertia, a price inflation-output gap variance tradeoff can be obtained by adding an ad hoc cost shock to the optimal price setting equation. $^{5}$ In our model, however, the variance tradeoff arises endogenously as a result of staggered nominal wage contracts, without making any departures from the optimizing-agent framework. The explanation for this result is straightforward in the special case where nominal wages are sticky and prices are completely flexible. In this case, the equilibrium real wage moves in response to preference and technology shocks, while the nominal wage only moves in response to changes in the output gap. Thus, if monetary policy maintains a constant price inflation rate, output must

\footnotetext{
${ }^{1}$ The seminal papers include Phelps and Taylor (1977), Taylor (1979), and Taylor (1980). Some recent examples include Bryant, Hooper, and Mann (1993); Henderson and McKibbin (1993); Tetlow and von zur Muehlen (1996); Williams (1997); Levin, Wieland, and Williams (1998); Rudebusch and Svensson (1998).

${ }^{2}$ King and Wolman (1998) and Goodfriend and King (1997) assume that price contracts are of the Taylor (1980) type, while Rotemberg and Woodford (1997) and Rotemberg and Woodford (1998) assume that price contracts are of the Calvo (1983) type.

${ }^{3}$ Levin (1989) formulates and estimates an optimizing agent model with staggered wage contracts and flexible prices and finds that productivity shocks induce an output-inflation variance tradeoff. More recently, Blanchard (1997) has outlined a simple static model with predetermined nominal wages to illustrate conditions under which inflation targeting fails to stabilize the output gap.

${ }^{4}$ Calvo (1983) suggested the timing features of these contracts, and Yun (1996) used such price contracts in a stochastic, optimizing-agent model. Kollmann (1997), Erceg (1997), and Kim (1997) make similar assumptions about about wage and price determination.

${ }^{5}$ Kiley (1998) shows that adding a shock to an optimal price-setting equation of the form derived by, e.g. Yun (1996), generates an output-gap/price-inflation tradeoff.
} 
temporarily deviate from potential to induce nominal wage adjustment, so that the real wage can move toward its new equilibrium value.

In this paper, we focus on a monetary policy frontier defined in terms of the variances of price inflation, wage inflation, and the output gap. ${ }^{6}$ This policy frontier has the property that the variance of any particular variable cannot be reduced without increasing the variance of one or both of the other variables. The remainder of this paper characterizes the policy frontier under various assumptions about nominal wage and price inertia. In determining the conditions for existence of a unique stationary rational expectations equilibrium, we find the novel result that the monetary policy rule need not include a nominal anchor when wages or prices or both are sticky. ${ }^{7}$

Section 2 outlines the model. In Section 3, we analyze restrictions on the set of feasible monetary policy choices that can be derived solely from the aggregate supply block of the model. In subsequent sections, we characterize features of the monetary policy tradeoff frontier (between output gap, price inflation, and wage inflation volatility) implied by the fully specified model. We examine a special case of the model with sticky wages and flexible prices for which the frontier can be computed analytically (Section 4), and then consider the general case in which both wages and prices are determined by overlapping nominal contracts (Section 5). In the general case, we use analytical methods to derive the endpoints of the policy frontier and numerical methods to characterize the complete frontier. Conclusions are given in Section 6.

\section{The Model}

Our model has a neoclassical structure in which households maximize utility subject to an intertemporal budget constraint, and firms maximize profits subject to given factor prices. Households are monopolistic competitors in the labor market, while firms are monopolistic competitors in the product market. We introduce nominal rigidities by assuming that households set their wages and firms set their prices in Calvo-style staggered contracts. All households face identical preference shocks, and all firms face identical productivity shocks. The sole source of heterogeneity among households and firms is that they adjust their nominal contracts at different times. Households fully insure against idiosyncratic consumption risk, but they cannot insure against idiosyncratic variation in leisure (resulting from wage dispersion across households).

\footnotetext{
${ }^{6}$ Monetary policy frontiers defined over the variances of price inflation and the output gap have been analyzed since at least the late 1970's. For references, see footnote 1. The specification in the text can be defended by appealing to the optimization problems of households in our model. Admittedly, this specification excludes some variables (such as interest rate volatility) that may be of concern to the monetary authorities. The appropriate specification of the monetary policy objective function is the subject of ongoing research.

${ }^{7}$ Recent contributions to the analysis of determinacy in monetary models include Woodford (1994), Woodford (1995), Clarida, Gali, and Gertler (1997), and Benhabib, Schmitt-Grohe, and Uribe (1998). Additional contributions which emphasize the implications of the interaction of monetary and fiscal policy for determinacy are Leeper (1991), Sims (1994), Woodford (1996), and Schmitt-Grohe and Uribe (1998).
} 


\subsection{Household Behavior}

A continuum of households is distributed on the unit interval, $h \in[0,1]$. Household $h$ is a monopolistically competitive seller of its unique labor input. The ratio of the demand for its labor, $L_{h, s}$, to the demand for aggregate labor, $L_{s}$, is inversely related to the ratio of its wage, $W_{h, s}$, to the aggregate wage, $W_{s}$ :

$$
\frac{L_{h, s}}{L_{s}}=\left(\frac{W_{h, s}}{W_{s}}\right)^{\frac{1}{\theta_{W^{-1}}}}
$$

where $0<\theta_{W}<1^{8}$

As a way of introducing nominal wage inertia into the model, we assume that wages are set in Calvo-style staggered contracts. In each period, there is a probability $\left(1-\xi_{W}\right)$ that household $h$ will be allowed to reset its contract wage. The wages of households that are not allowed to reset their contract wages grow at the mean rate of gross inflation $\Pi$. Thus, if household $h$ has not adjusted its contract wage since period $t$, then its wage in period $s$ is

$$
W_{h, s}=W_{h, t} \Pi^{s-t} .
$$

The probability that a household will be allowed to reset its contract wage in period $s$ does not depend on how long its existing contract has been in effect, and is invariant to the aggregate state vector. Thus, a constant fraction $\left(1-\xi_{W}\right)$ of households are allowed to reset their contract wages each period.

The period utility function of household $h$ is separable in three arguments: consumption $\left(C_{h, s}\right)$ minus a consumption shock $\left(U_{s}\right)$, real money holdings (nominal money holdings, $M_{h, s}$, divided by the price of consumption, $P_{s}$ ) minus a real money shock $\left(V_{s}\right)$, and leisure (one minus hours worked, $\left.L_{h, s}\right)$ minus a leisure shock $\left(Z_{s}\right):^{9}$

${ }^{8} L_{s}$ is a labor index of the Dixit and Stiglitz (1977) form:

$$
L_{s}=\left[\int_{0}^{1} L_{h, s} \theta_{W} d h\right]^{\frac{1}{\theta_{W}}},
$$

where $L_{h, s}$ is the amount of household $h$ 's labor purchased by all firms. Firms minimize the cost of "producing" a unit of labor taking the wage of each household, $W_{h, s}$ as given. Firm $f$ 's demand for the labor of household $h$ implied by the cost minimization is

$$
L_{h, s}(f)=\left[\frac{W_{h, s}}{W_{s}}\right]^{\frac{1}{\theta_{W-1}}} L_{s}(f),
$$

where $L_{s}(f)$ is the amount of labor purchased by firm $f$, and the wage index, $W_{s}$,

$$
W_{s}=\left[\int_{0}^{1} W_{h, s}{ }^{\frac{\theta_{W}}{\theta_{W}-1}} d h\right]^{\frac{\theta_{W}-1}{\theta_{W}}},
$$

is the minimum cost of producing one unit of labor.

${ }^{9} C_{h, s}$ is a consumption index of the Dixit and Stiglitz (1977) form:

$$
C_{h, s}=\left[\int_{0}^{1} C_{h, s}(f)^{\theta_{P}} d f\right]^{\frac{1}{\theta_{P}}}
$$




$$
\mathcal{U}\left(C_{h, s}, \frac{M_{h, s}}{P_{s}}, 1-L_{h, s}\right)=\frac{\left(C_{h, s}-U_{s}\right)^{1-\sigma}}{(1-\sigma)}+\frac{\left(\frac{M_{h, s}}{P_{s}}-V_{s}\right)^{1-v}}{(1-v)}+\frac{\left(1-L_{h, s}-Z_{s}\right)^{1-\chi}}{1-\chi}
$$

The three shocks are common to all households and have positive means $\bar{U}, \bar{V}$, and $\bar{Z}$. Increases in the consumption, money, and leisure shocks increase the demands for consumption, real money, and leisure, respectively, because each shock raises the marginal utility of a given amount of the corresponding "good ."10

Household $h$ 's budget constraint in period $s$ states that consumption expenditure plus asset accumulation must equal disposable income: ${ }^{11}$

$$
\begin{gathered}
P_{s} C_{h, s}+M_{h, s}-M_{h, s-1}+\int_{\Psi_{s+1}} \delta_{s+1, s}(\psi) B_{h, s}(\psi) d \psi-B_{h, s-1} \\
=W_{h, s} L_{h, s}+\Gamma_{s}+T_{h, s} .
\end{gathered}
$$

where $\Psi_{s+1}$ is the state space for period $s+1$. Asset accumulation consists of increases in money holdings and the acquisition of state contingent claims, where $\delta_{s+1, s}(\psi)$ represents the price in period $s$ of a claim to one dollar in state $\psi$ in period $s+1$, and $B_{h, s}(\psi)$ is the quantity of such claims. A state is defined not only by the realizations of the common shocks but also by designations of which households are allowed to adjust their wages. ${ }^{12}$ Household $h$ receives labor income, $W_{h, s} L_{h, s}$; an aliquot share of aggregate profits, $\Gamma_{s}$; and a lump sum cash transfer from the government, $T_{h, s} \cdot{ }^{13}$

where $C_{h, s}(f)$ represents purchases by household $h$ of the differentiated good produced by firm $f$ in period $s$. Household $h$ minimizes the cost of "producing" a unit of consumption taking the prices of the differentiated consumption goods, $P_{f, s}$ as given. Household $h$ 's demand for good $f$ implied by the cost minimization is

$$
C_{h, s}(f)=\left[\frac{P_{f, s}}{P_{s}}\right]^{\frac{1}{\theta_{P}-1}} C_{h, s}
$$

where the price index, $P_{s}$,

$$
P_{s}=\left[\int_{0}^{1} P_{f, s^{\frac{\theta_{P}}{\theta_{P}-1}} d f}\right]^{\frac{\theta_{P}-1}{\theta_{P}}},
$$

is the minimum cost of producing one unit of consumption.

We follow the usual practice of omitting negative one in the numerator of each of the terms of the period utility function. As is well known, it is necessary to include negative ones if the limits of the terms as $\sigma, \lambda, \chi \rightarrow 1$ are to be the logarithms of the arguments.

${ }^{10}$ It is common to interpret $U_{s}$ as a government spending shock.

${ }^{11}$ Equation (4) is a reduced form of the full budget constraint. It is obtained by substituting the product $P_{s} C_{h, s}$ for the sum of the products of the prices and quatitities of the individual differentiated goods consumed.

${ }^{12}$ The common shocks include not only $U_{s}, Z_{s}$, and $V_{s}$, but also the productivity shock, $X_{s}$, which is discussed below.

${ }^{13}$ These aliquot shares exhaust aggregate profits:

$$
\int_{0}^{1} \Gamma_{s} d h=\int_{0}^{1}\left[P_{f, s} Y_{f, s}-W_{s} L_{s}(f)\right] d f
$$

where $Y_{f, s}$ is the output of firm $f$. Cash transfers are the way the supply of nominal money is changed. 
A wage-setting household $h$ maximizes its utility functional with respect to the choice of its consumption, its holdings of money, its holdings of contingent claims, and its nominal wage,

$$
\max _{\substack{\left\{C_{h, t}, M_{h, t}, B_{h, t}, W_{h, t}\right\}}} \mathcal{E}_{t} \sum_{s=t}^{\infty}(\beta)^{s-t} \mathcal{U}\left(C_{h, s}, \frac{M_{h, s}}{P_{s}}, 1-L_{h, s}\right),
$$

subject to the demand for its labor, equation (1), and its budget constraint, equation $(4)$, where $\mathcal{E}_{t}$ indicates an expectation based on period $t$ information. The discount factor $\beta$ satisfies $0<\beta<1$. The first-order conditions for the household's problem $\operatorname{are}^{14}$

$$
\begin{gathered}
\mathcal{U}_{1 ; h, t}=\mathcal{E}_{t}\left[\left(1+I_{t}\right) \frac{P_{t}}{P_{t+1}} \beta \mathcal{U}_{1 ; h, t+1}\right]=\mathcal{E}_{t}\left[R_{t} \beta \mathcal{U}_{1 ; h, t+1}\right] \\
\frac{\delta_{t+1, t}(\psi) \mathcal{U}_{1 ; h, t}}{P_{t}}=\frac{\operatorname{Prob}(\psi) \beta \mathcal{U}_{1 ; h, t+1}(\psi)}{P_{t+1}(\psi)}, \quad \text { for all } \psi \in \Psi_{t+1} \\
\mathcal{U}_{1 ; h, t}=\left(\frac{1+I_{t}}{I_{t}}\right) \mathcal{U}_{2 ; h, t} \\
\mathcal{E}_{t} \sum_{s=t}^{\infty}\left(\xi_{W} \beta\right)^{s-t} \mathcal{U}_{1 ; h, s}\left(\frac{\Pi^{s-t} W_{h, t} \theta_{W}}{P_{s}}\right) L_{h, s}=\mathcal{E}_{t} \sum_{s=t}^{\infty}\left(\xi_{W} \beta\right)^{s-t} \mathcal{U}_{3 ; h, s} L_{h, s},
\end{gathered}
$$

where $\operatorname{Prob}(\psi)$ represents the probability of state $\psi$, and

$$
1+I_{t}=\frac{1}{\int_{\Psi_{t+1}} \delta_{t+1, t}(\psi) d \psi}
$$

Equations (6), (7), and (8) are standard conditions for consumption, state contingent claims, and money holdings. According to equation (6), the marginal utility of consumption in period $t$ must equal the expectation of the gross real interest rate, $R_{t}$, multiplied by the marginal utility of consumption in period $t+1$. According to equation (7), the price of a claim to a "dollar" in state $\psi$ in period $t+1$ multiplied by the marginal utility of a dollar in period $t$ must equal the discounted marginal utility of a dollar in period $t+1$ in state $\psi$ multiplied by the probability that state $\psi$ occurs. According to equation (8), the marginal utility of consumption in period $t$ must equal the product of $\frac{1+I_{t}}{I_{t}}$ multiplied by marginal utility of real money holdings in period $t$, where $\frac{1+I_{t}}{I_{t}}$ is inversely related to the nominal interest rate, $I_{t}$.

The first-order condition for the wage, equation (9), may be unfamiliar to some. A household sets its wage so that the expected marginal reward (the sum of discounted

${ }^{14}$ The marginal utilities are

$$
\mathcal{U}_{1 ; h, s}=\left(C_{h, s}-U_{s}\right)^{-\sigma}, \mathcal{U}_{2 ; h, s}=\left(\frac{M_{h, s}}{P_{s}}-V_{s}\right)^{-v}, \mathcal{U}_{3 ; h, s}=\left(1-L_{h, s}-Z_{s}\right)^{-\chi}
$$


expected products of marginal utilities of consumption and real wages, divided by the wage markup, $\frac{1}{\theta_{W}}$ ) equals its expected marginal sacrifice (the sum of discounted expected marginal utilities of leisure). Expectations are conditioned on the household's not being able to reset its wage. In the limiting case in which all households are allowed to set their wages every period $\left(\xi_{W} \rightarrow 0\right)$, equation $(9)$ reduces to the condition that the marginal return to work in consumption terms (the household's real wage divided by the wage markup) equal the marginal cost of work in consumption terms (the marginal utility of leisure divided by the marginal utility of consumption): ${ }^{15}$

$$
\mathcal{U}_{1 ; h, t} \frac{W_{h, t} \theta_{W}}{P_{t}}=\mathcal{U}_{3 ; h, t}
$$

\subsection{Firm Behavior}

A continuum of firms is distributed on the unit interval, $f \in[0,1]$. Firm $f$ is a monopolistically competitive seller of its unique good. The ratio of the demand for firm $f$ 's output $\left(Y_{f, s}\right)$ to aggregate output $\left(Y_{s}\right)$ is inversely related to the ratio of firm $f^{\prime}$ 's price $\left(P_{f, s}\right)$ to the aggregate price $\left(P_{s}\right):{ }^{16}$

$$
\frac{Y_{f, s}}{Y_{s}}=\left(\frac{P_{f, s}}{P_{s}}\right)^{\frac{1}{\theta_{P^{-1}}}},
$$

where $0<\theta_{P}<1$.

As a way of introducing nominal price inertia into the model, we assume that prices, like wages, are set in Calvo-style staggered contracts. Each period there is a probability $\left(1-\xi_{P}\right)$ that firm $f$ will be allowed to reset its contract price. The prices of firms that are not allowed to reset their contract prices grow at the mean rate of gross inflation $\Pi$. Thus, if firm $f$ has not adjusted its contract price since period $t$, then its price in period $s$ is

$$
P_{f, s}=P_{f, t} \Pi^{s-t}
$$

The probability that a firm will be allowed to reset its contract price in period $s$ does not depend on how long its existing contract has been in effect, and is invariant to the aggregate state vector. Thus, a constant fraction $\left(1-\xi_{P}\right)$ of firms are allowed to reset their contract prices each period.

All firms have identical Cobb-Douglass production functions in capital and labor hours (with capital elasticity $\alpha$ ), and can purchase all the capital and labor they want at prevailing factor prices. Furthermore, capital and labor are perfectly mobile across firms. Therefore, all firms have the same marginal cost $\left(M C_{s}\right)$ which can be written as a function of the fixed supply of capital $(\bar{K})$, labor $\left(L_{s}\right)$, the wage $\left(W_{s}\right)$, and a

\footnotetext{
${ }^{15}$ In order to confirm the assertion in the text, note that $\lim _{\xi_{W} \rightarrow 0}\left(\xi_{W} \beta\right)^{0}=1$.

${ }^{16}$ Demand for firm $f$ 's good is obtained by summing households' demand for this good which is derived in a previous footnote.
} 
productivity shock $\left(X_{s}\right):{ }^{17}$

$$
M C_{s}=\frac{W_{s} L_{s}^{\alpha}}{(1-\alpha) \bar{K}^{\alpha} X_{s}}
$$

Note that an increase in the productivity shock reduces marginal cost.

A price-setting firm $f$ maximizes its profit functional with respect to its contract price $P_{f, t}$ :

$$
\max _{\left\{P_{f, t}\right\}} E_{t}\left[\sum_{s=t}^{\infty}\left(\xi_{P} \beta\right)^{s-t} \delta_{s, t}\left(P_{f, s}-M C_{s}\right) Y_{f, s}\right] .
$$

The first-order condition for a price-setting firm is

$$
\mathcal{E}_{t} \sum_{s=t}^{\infty}\left(\xi_{P} \beta\right)^{s-t} \delta_{s, t} \frac{\Pi^{s-t} P_{f, t}}{P_{s}} Y_{f, s}=\frac{1}{\theta_{P}} \mathcal{E}_{t} \sum_{s=t}^{\infty}\left(\xi_{P} \beta\right)^{s-t} \delta_{s, t} \frac{M C_{s}}{P_{s}} Y_{f, s} .
$$

Each firm sets its price so that the sum of discounted real revenue terms is equal to the price markup $\left(\frac{1}{\theta_{P}}\right)$ multiplied by the sum of discounted real marginal costs. Expectations are conditioned on the firm's not being able to reset its price. In the limiting case in which all firms are allowed to set their prices every period $\left(\xi_{P} \rightarrow 0\right)$, equation (16) reduces to the condition (familiar from standard imperfect competition analysis) that the real wage equal the marginal value product of labor (the marginal product of labor divided by the price markup): ${ }^{18}$

$$
\frac{W_{s}}{P_{f, t}}=\theta_{P}(1-\alpha) \bar{K}^{\alpha} L_{s}^{-\alpha} X_{s}
$$

\subsection{Approximation of the General Model}

Approximations of the basic relationships of the general model appears in Table 1. Lowercase letters represent deviations of natural logarithms of variables from their steady state values, except for $i_{t}$ which represents the deviation of the nominal interest rate from its steady state value.

\footnotetext{
${ }^{17}$ The derivation of the marginal cost function is standard. Minimize costs $W_{s} L_{s}(f)+P_{s}^{K} K_{s}(f)$, where $L_{s}(f)$ and $K_{s}(f)$ are the amounts of labor and capital, respectively, purchased by firm $f$, subject to the constraint that a fixed level of output be equal to the production function $\bar{Y}_{f, s}=$ $X_{s} K_{s}(f)^{\alpha} L_{s}(f)^{1-\alpha}$. Solve for the firm's capital-labor ratio as a function of relative factor prices. Use this expression to eliminate $P_{s}^{K} K_{s}(f)$ from the expression for the firm's total costs. The resulting expression depends only wage costs and shocks. Use the firm's production function to obtain an expression for its labor input in terms of its capital-labor ratio and its output. Substitute this expression into the expression for total costs in terms of wage costs and differentiate with respect to the firm's output to obtain the expression for the firm's marginal cost noting that the firm's capital-labor ratio does not change because it depends on economy-wide factor prices. Finally, replace the firm's capital-labor ratio with the aggregate capital-labor ratio.

${ }^{18}$ In order confirm this assertion, note that $\lim _{\xi_{P} \rightarrow 0}\left(\xi_{P} \beta\right)^{0}=1$ and that $\delta_{t, t}=1$.
} 


\section{Table 1: The General Model}

\section{Demand Block}

$$
\begin{aligned}
g_{t}=- & \frac{1}{\sigma \ell_{C}}\left(i_{t}-\pi_{t+1 \mid t}\right)+g_{t+1 \mid t} \\
& -y^{*}+y_{t+1}^{*}+\frac{\bar{\ell}_{U}}{\bar{\ell}_{C}}\left(u_{t}-u_{t+1 \mid t}\right) \quad \text { (goods demand) }
\end{aligned}
$$

\section{Supply Block}

$$
\begin{array}{ll}
\omega_{t}=\beta \omega_{t+1 \mid t}+k_{W}\left(\zeta_{t}^{s}-\zeta_{t}\right) & \text { (wage setting) } \\
\zeta_{t}^{s}=\zeta_{t}^{*}+\left(\frac{\Delta}{1-\alpha}-\frac{\alpha}{1-\alpha}\right) g_{t} & \text { (supply real wage) } \\
\pi_{t}=\beta \pi_{t+1 \mid t}+k_{P}\left(\zeta_{t}-\zeta_{t}^{d}\right) & \text { (price setting) } \\
\zeta_{t}^{d}=\zeta_{t}^{*}-\frac{\alpha}{1-\alpha} g_{t} & \text { (demand real wage) } \\
\zeta_{t}=\zeta_{t-1}+\omega_{t}-\pi_{t} & \text { (real wage change) } \\
\zeta_{t}^{s}-\zeta_{t}^{d}=\left(\frac{\Delta}{1-\alpha}\right) g_{t} & \text { (real-wage gap/output gap) }
\end{array}
$$

\section{Monetary Block}

$i_{t}=\gamma_{\pi} \pi_{t}+\gamma_{\omega} \omega_{t}+\gamma_{g} g_{t}+\gamma_{x} x_{t}+\gamma_{x_{-1}} x_{t-1} \quad$ (monetary rule)

Complete Flexibility Equilibrium

$$
\begin{array}{ll}
y_{t}^{*}=\frac{(1-\alpha) \sigma \bar{\ell}_{U}}{\Delta} u_{t}+\frac{1+\chi \bar{\ell}_{L}}{\Delta} x_{t}-\frac{(1-\alpha) \chi \bar{\ell}_{Z}}{\Delta} z_{t} & \text { (potential output) } \\
\zeta_{t}^{*}=-\frac{\alpha \sigma \bar{\ell}_{U}}{\Delta} u_{t}+\frac{\alpha \chi \bar{\ell}_{L}}{\Delta} z_{t}+\frac{\chi \bar{\ell}_{L}+\sigma \bar{\ell}_{C}}{\Delta} x_{t} & \text { ( complete flexibility real wage) }
\end{array}
$$

\section{Definitions}

$$
\begin{aligned}
& g_{t}=y_{t}-y_{t}^{*}, \zeta_{t}=w_{t}-p_{t}, \pi_{t}=p_{t}-p_{t-1}, \omega_{t}=w_{t}-w_{t-1} \\
& \Delta=\alpha+\chi \bar{\ell}_{L}+(1-\alpha) \sigma \bar{\ell}_{C} \\
& \bar{\ell}_{C}=\frac{\bar{C}}{\bar{C}-\bar{U}}, \bar{\ell}_{Y}=\frac{\bar{Y}}{\bar{Y}-\bar{U}}, \bar{\ell}_{U}=\frac{\bar{U}}{\bar{C}-\bar{U}}, \bar{\ell}_{L}=\frac{\bar{L}}{1-\bar{L}-\bar{Z}}, \bar{\ell}_{Z}=\frac{\bar{Z}}{1-\bar{L}-\bar{Z}} \\
& k_{P}=\left(\frac{\left(1-\xi_{P} \beta\right)\left(1-\xi_{P}\right)}{\xi_{P}}\right), k_{W}=\left(\frac{\left(1-\xi_{W} \beta\right)\left(1-\xi_{W}\right)}{\xi_{W}\left(1-\chi \bar{\ell}_{L} \epsilon_{L, W}\right)}\right)
\end{aligned}
$$


These relationships are expressed in terms of the output gap, $g_{t}$ (the difference between actual output, $y_{t}$, and "potential" output, $y_{t}^{*}$ ), because the output gap features prominently in our analysis. Potential or "notional" output is the output level that would obtain in the absence of nominal inertia. ${ }^{19}$

The demand block of the model comprises the single equation $(T 1.1)$ which we refer to as the "goods demand equation." 20 This equation follows from the standard approximation of the first order condition (6) governing the path of consumption (with consumption at each date replaced by output, reflecting equilibrium conditions),

$$
y_{t}=-\frac{1}{\sigma \bar{\ell}_{C}}\left(i_{t}-\pi_{t+1 \mid t}\right)+y_{t+1 \mid t}+\frac{\bar{\ell}_{U}}{\bar{\ell}_{C}}\left(u_{t}-u_{t+1 \mid t}\right) \text {. }
$$

Equation (18) states that aggregate demand depends negatively on the real interest rate and expected future consumption shocks and depends positively on expected future output and the current consumption shock. ${ }^{21}$ Solving forward equation (18) yields an equation in which the demand for goods depends negatively on an unweighted sum of future short-term real interest rates, naturally interpreted as the "long-term real interest rate." 22

The supply block comprises equations (T1.2) through (T1.7). The wage setting equation (T1.2) is a log-linear approximation to the first-order condition (9) with a number of substitutions. ${ }^{23}$ Solving equation (T1.2) forward yields an equation that states that the deviation of wage inflation from its steady state value depends positively on the present discounted value of the sum of all expected future deviations of the supply real wage from the actual real wage. Equation (T1.3) characterizes the supply real wage, $\zeta_{t}^{s}$, which is the notional real wage that would prevail if all households could adjust their wages in the current period (that is, if $\xi_{W}=0$ so that $\left.\kappa_{W} \rightarrow \infty\right)$. Equation (T1.3) follows from two standard relations. The first relation is the standard approximation for the supply real wage,

$$
\zeta_{t}^{s}=\chi \bar{\ell}_{L} l_{t}+\sigma \bar{\ell}_{C} y_{t}+\chi \bar{\ell}_{Z} z_{t}-\sigma \bar{\ell}_{U} u_{t}
$$

\footnotetext{
${ }^{19}$ In earlier contributions to the disequilibrium literature, complete flexibility models are referred to as notional models because they apply in the purely hypothetical case of complete price and wage flexibility. For references to this literature see Quandt (1987) and the references in Henderson and $\operatorname{Kim}(1998)$.

${ }^{20}$ It is often referred to as the "IS curve."

${ }^{21}$ To arrive at $(T 1.1)$, replace $y_{t}$ with $g_{t}+y_{t}^{*}$.

${ }^{22}$ Here and elsewhere "solving an equation forward" means using expectations of forwarded versions of the equation based on period $t$ information to rewrite the equation so that the period $t$ value of a variable depends among other things on the expectation of that variable in period $t+k$, a quantity that approaches zero as $k$ approaches infinity in a stationary rational expectations equilibrium.

The model also includes a money market equilibrium condition:

$$
v \bar{\ell}_{M / P}\left(m_{t}-p_{t}\right)=-i_{t}+\bar{\ell}_{C} y_{t}-\bar{\ell}_{V} v_{t}-\bar{\ell}_{U} u_{t}
$$

This condition is an approximation of the first order condition governing the holding of real balances, equation (7), with desired nominal money holdings replaced by actual holdings to reflect an equilibrium condition.

${ }^{23}$ See Appendix B.
} 
Thus, the supply real wage rises with the amount of labor supplied, output (which replaces consumption, reflecting an equilibrium condition ), and a positive leisure shock, and falls with a positive consumption shock. The second relation is the standard approximation of the production function,

$$
y_{t}=(1-\alpha) l_{t}+x_{t},
$$

which states that output increases with the amount of labor input and positive productivity shocks. ${ }^{24}$

The price setting equation (T1.4) is a log-linear approximation to the first-order condition (16) with a number of substitutions. ${ }^{25}$ Solving equation (T1.4) forward yields an equation that states that the deviation of price inflation from its steady state value depends positively on the sum of the present discounted value of all expected future deviations of the actual real wage from the demand real wage. Equation (T1.5) characterizes the demand real wage, $\zeta_{t}^{d}$, which is the notional real wage that would prevail if all firms could adjust their prices in the current period (that is, if $\xi_{P}=0$ so that $\left.\kappa_{P} \rightarrow \infty\right)$. This equation follows from the standard approximation for the demand real wage,

$$
\zeta_{t}^{d}=-\alpha l_{t}+x_{t}
$$

which states that the demand real wage decreases with the amount of labor employed and increases with positive productivity shocks. ${ }^{26}$

Equation (T1.6) states that the change in the actual real wage, $\zeta_{t}$, equals the difference between wage inflation and price inflation. Equation $(T 1.7)$, which is implied by equations (T1.3) and (T1.5), states that the output gap is proportional to the gap between the supply and demand real wages.

The monetary rule equation (T1.8) states that the interest rate is increased above its steady state value if price inflation, wage inflation, or the gap between actual and potential output are above their steady state values. ${ }^{27}$

Equation (T1.9) expresses potential output in terms of the three shocks $\left(u_{t}, x_{t}\right.$, and $z_{t}$ ). Equation (T1.10) provides a similar expression for the complete flexibility real wage, $\zeta_{t}^{*}$, the real wage that would prevail in the absence of nominal inertia (i.e. if $\left.\xi_{P}=\xi_{W}=0\right) .{ }^{28}$ Both potential output and the complete flexibility real wage depend

\footnotetext{
${ }^{24}$ To arrive at (T1.3) eliminate $l_{t}$ from equation (11) using equation (20) and replace $y_{t}$ with $g_{t}+y_{t}^{*}$ in the resulting expression. The production function gives $y_{t}$ as a function of $l_{t}$ and $x_{t}$ alone because the capital stock is assumed to be fixed.

${ }^{25}$ We do not describe those substitutions in this paper. They are described by Yun (1996) whose approach we follow closely and are very similar to the substitutions used to derive the wage setting equation (T1.2) which are described in Appendix B.

${ }^{26}$ To arrive at $(T 1.5)$ eliminate $l_{t}$ from (21) using equation (20), and replace $y_{t}$ with $g_{t}+y_{t}^{*}$ in the resulting expression.

${ }^{27}$ Throughout this paper we restrict our attention to cases in which all the $\gamma_{i}$ are non-negative. In some cases, stationary, rational-expectations equilibria exist for negative values of these parameters, as is apparent from the expressions for roots in Appendix A, but we have not studied these cases in detail.

${ }^{28}$ Equations (T1.9) and (T1.10) are obtained by assuming that $\zeta_{t}^{s}=\zeta_{t}^{d}=\zeta_{t}^{*}$ and using (19), (20), and (21) to solve for $\zeta_{t}^{*}, y_{t}^{*}$, and $l_{t}^{*}$ in terms of $u_{t}, x_{t}$, and $z_{t}$.
} 
on the consumption shock, $u_{t}$, because this shock affects not only goods demand but also the supply real wage. The three shocks $u, x$, and $z$ are assumed to be mutually uncorrelated and to follow first order autoregressive processes with serial correlation coefficients $\rho_{j}, j=u, x, z$ and innovations $\varepsilon_{j}, j=u, x, z$.

\section{Variance Implications of the Supply Block}

In this section, we examine key implications of the aggregate supply block of the model. We examine two special cases of the model: the sticky price version, in which prices are sticky and wages are flexible, and the sticky wage version, in which wages are sticky and prices are flexible. The wage-setting equation of the sticky wage version is formally similar to the price-setting equation of the sticky price version, but the implications of price inflation stabilization are very different in the two versions. Finally, we show that it is impossible to stabilize more than one of the three policy frontier variables in the general model. We assume the existence of a stationary rational expectations equilibrium throughout this section, deferring analysis of existence and uniqueness conditions until later in the paper.

\subsection{Sticky Prices and Flexible Wages}

In the sticky price version, wages are completely flexible (i.e., $\xi_{W}$ equals zero, so that $k_{W}$ approaches $\infty$ ), so households are always on their supply real wage schedule (the inverse of their labor supply curve). Since the real wage equals the supply real wage $\left(\zeta_{t}=\zeta_{t}^{s}\right)$, the price setting equation (T1.4) implies that price inflation varies directly with the difference between the supply real wage (the marginal cost of labor) and the demand real wage (the firm's marginal product of labor). Figure 1 displays the relations between the output gap and the supply and demand real wages,

respectively. Disequilibrium in the labor market (measured by $\zeta_{t}^{s}-\zeta_{t}^{d}$ ) is proportional to disequilibrium in the goods market (measured by $g_{t}$ ). Therefore, the price-setting relation can be expressed in terms of current and expected future price inflation and the output gap:

$$
\pi_{t}=\beta \pi_{t+1 \mid t}+\lambda_{P} g_{t}, \quad \lambda_{P}=k_{P}\left(\frac{\Delta}{1-\alpha}\right) .
$$

Price inflation varies directly with the output gap because firms must pay their employees higher real wages to induce them to work additional hours, while the marginal product of labor declines.

In this special case, we obtain the following results.

Proposition 1: In the version with sticky prices and flexible wages $\left(\xi_{P}>0\right.$ and $\left.\xi_{W}=0\right)$,

(a) $\sigma_{\pi}^{2}=0$ if and only if $\sigma_{g}^{2}=0$

(b) if $\sigma_{\pi}^{2}=\sigma_{g}^{2}=0$, then $\sigma_{\omega}^{2}>0$

(c) if $\sigma_{\omega}^{2}=0$, then $\sigma_{\pi}^{2}>0$ and $\sigma_{g}^{2}>0$ 
Proof: See Appendix A.

According to Proposition 1(a), stabilizing price inflation stabilizes the output gap, and conversely. Proposition 1(a) follows immediately from the form of the price setting relation (22) in a stationary equilibrium. If the output gap is stabilized, the real wage must equal the complete flexibility real wage, which is affected by all shocks from equation (T1.10). Proposition 1(b) indicates that if price inflation and the output gap are stabilized, wage inflation must vary to generate the required real wage adjustment. Proposition 1(c) indicates that if wage inflation is stabilized, then stabilizing price inflation and the output gap is impossible because the required real wage adjustment would be precluded.

\subsection{Sticky Wages and Flexible Prices}

In the sticky wage version, prices are completely flexible (i.e., $\xi_{P}$ equals zero so that $k_{P}$ approaches infinity), so firms are always on their demand real wage schedule (the inverse of their labor demand curve). Since the real wage equals the demand real wage $\left(\zeta_{t}=\zeta_{t}^{d}\right)$, the wage-setting equation $(T 1.2)$ implies wage inflation varies directly with the difference between the supply real wage and the demand real wage. Therefore, the wage-setting relation can be expressed in terms of current and expected future wage inflation and the output gap:

$$
\omega_{t}=\beta \omega_{t+1 \mid t}+\lambda_{W} g_{t}, \quad \lambda_{W}=k_{W}\left(\frac{\Delta}{1-\alpha}\right) .
$$

The following proposition establishes the existence of a variance tradeoff between price inflation and the output gap. As we show later, such a tradeoff exists under much more general conditions.

Proposition 2 : In the version with sticky wages and flexible prices $\left(\xi_{W}>0\right.$ and $\left.\xi_{P}=0\right)$,

(a) $\sigma_{\omega}^{2}=0$ if and only if $\sigma_{g}^{2}=0$

(b) if $\sigma_{\omega}^{2}=\sigma_{g}^{2}=0$, then $\sigma_{\pi}^{2}>0$

(c) if $\sigma_{\pi}^{2}=0$, then $\sigma_{\omega}^{2}>0$ and $\sigma_{g}^{2}>0$

Proof: See Appendix A.

The results stated in this proposition reflect the formal similarity of equations (22) and (23). According to Proposition 2(a), stabilizing wage inflation stabilizes the output gap, and conversely. Proposition $2(a)$ follows immediately from the form of equation (23). Proposition 2(b) indicates that if wage inflation and the output gap are stabilized, price inflation must vary to generate the required real wage adjustment. Proposition $2 c$ ) indicates that if price inflation is stabilized, then stabilizing wage inflation and the output gap is impossible because the required real wage adjustment would be precluded. 
Figure 2 illustrates Proposition 2(c) for the case of i.i.d. shocks. It is assumed that some shock has shifted the supply and demand real wage schedules so that the complete flexibility equilibrium is at point $\left(g_{t}=0, \zeta_{t}=\zeta_{t}^{*}\right)$ instead of at the previous point $\left(g_{t}=0, \zeta_{t-1}=\zeta_{t-1}^{*}=0\right)$. The $\pi=0$ schedule shows the pairs of $\zeta_{t}$ and $g_{t}$ that are consistent with complete stabilization of price inflation. If price inflation is stabilized, then the real wage can rise only if the output gap is positive so that wages rise. The $\pi=0$ schedule is upward sloping and passes through the previous point. ${ }^{29}$ With sticky wages and flexible prices, the real wage must also be on the demand real wage schedule $\left(\zeta_{t}^{d}\right)$. With complete stabilization of price inflation, the new equilibrium is at the intersection of the $\pi=0$ schedule and the $\zeta_{t}^{d}$ schedule. Real wages rise less than if prices were fully flexible, and the output gap is positive. If wage inflation is less sensitive to the output gap, the $\pi=0$ schedule is flatter, so the output costs of strict inflation targeting are greater.

Propositions 1 and 2 are helpful in reconciling two strands of the literature. On the one hand, some recent studies have demonstrated that there is no outputgap/price-inflation variance tradeoff in dynamic general equilibrium models with optimizing agents, staggered price setting, and completely flexible wages. ${ }^{30}$ The stickyprice/flexible-wage version of our model is designed to replicate these results. In particular, our price setting relation (22) is the essentially the same as the price setting relations implied by the models used to derive the no-tradeoff results (with the minor difference that some of these price setting relations contain additional leads/lags of the output gap).

On the other hand, a tradeoff has been shown to exist in sticky price models that depart from a strict optimizing framework. ${ }^{31}$ The key to understanding this divergence is the recognition that in the latter class of models, the tradeoff results from "tacking on" a shock, $\phi_{t}$, to an optimization-based price-setting equation like (22) to obtain a price-setting equation of the form:

$$
\pi_{t}=\beta \pi_{t+1 \mid t}+\lambda_{W} g_{t}+\phi_{t}
$$

It is evident from equation (24) that this specification implies an output-inflation volatility tradeoff. ${ }^{32}$

In contrast, a tradeoff arises endogenously in the sticky wage/flexible price version of our model. The price-setting equation implied by this version is ${ }^{33}$

\footnotetext{
${ }^{29}$ In section 5 we provide a complete analysis of what happens when inflation is completely stabilized $\left(\pi_{t+j \mid t}=0, j=0, \ldots, \infty\right)$. According to that analysis, the reduced-form expression for wage inflation is $\omega_{t}=\left(a_{0}-1\right) \zeta_{t-1}+c_{\omega u} u_{t}+c_{\omega x} x_{t}+c_{\omega z} z_{t}$, where $0<a_{0}<1$ is defined in Table 2. Therefore, in the case of i.i.d. shocks, expected wage inflation is $\omega_{t+1 \mid t}=\left(a_{0}-1\right) \zeta_{t}$, so the wage-setting equation can be rewritten as $\omega_{t}=\beta\left(a_{0}-1\right) \zeta_{t}+\kappa_{W} \kappa g_{t}$. With $\pi_{t}=0$ and the lagged real wage at its steady state value of zero $\left(\zeta_{t-1}=\zeta_{t-1}^{*}=0\right)$, the real wage change equation $(T 1.6)$ implies that $\omega_{t}=\zeta_{t}$. Combining the last two equations by eliminating $\omega_{t}$ and solving for $\zeta_{t}$ yields the equation for the $\pi=0$ schedule in the bottom panel of Figure 1, $\zeta_{t}=\left(\frac{\lambda_{W}}{2-a_{0}}\right) g_{t}$.

${ }^{30}$ See the references in footnote 2.

${ }^{31}$ See the reference in footnote 5 .

${ }^{32}$ If price inflation is completely stabilized (that is, $\pi_{t}=\pi_{t+1 \mid t}=0$ ), then the variance of the output gap is proportional to the variance of the disturbance $\phi_{t}$.

${ }^{33}$ Equation $(A .4)$ is solved for $\omega_{t}$, and the resulting equation and its forwarded version are used
} 


$$
\begin{gathered}
\pi_{t}=\beta \pi_{t+1 \mid t}+F(L) g_{t}+\phi_{t} \\
F(L)=-\left(\frac{\beta \alpha}{1-\alpha}\right) L^{-1}+\left[\frac{(1+\beta) \alpha}{1-\alpha}+\lambda_{W}\right]-\left(\frac{\alpha}{1-\alpha}\right) L \\
\phi_{t}=-\left(\frac{1}{1-\alpha}\right)\left[\beta\left(\alpha y_{t+1 \mid t}^{*}-x_{t+1 \mid t}\right)-(1+\beta)\left(\alpha y_{t}^{*}-x_{t}\right)+\left(\alpha y_{t-1}^{*}-x_{t-1}\right)\right]
\end{gathered}
$$

where $L$ is the lag operator. This price-setting equation has essentially the same form as equation (24), but the residual $\phi_{t}$ is an explicit function of the underlying preference and technology parameters and the exogenous shocks, rather than an ad hoc addition.

\subsection{Sticky Prices and Sticky Wages}

With a sticky wages and sticky prices, households are not on their supply real wage schedules unless wage inflation is completely stabilized, and firms are not on their demand real wage schedules unless price inflation is completely stabilized.

Proposition 3: In the version with sticky wages and prices $\left(\xi_{W}>0\right.$ and $\left.\xi_{P}>0\right)$,

(a) if $\sigma_{g}^{2}=0$, then $\sigma_{\pi}^{2}>0$ and $\sigma_{\omega}^{2}>0$

(b) if $\sigma_{\pi}^{2}=0$, then $\sigma_{g}^{2}>0$ and $\sigma_{\omega}^{2}>0$

(c) if $\sigma_{\omega}^{2}=0$, then $\sigma_{g}^{2}>0$ and $\sigma_{\pi}^{2}>0$

Proof: See Appendix A.

According to Proposition 3, assuming that it is feasible to set to zero the variance of any one of the three policy-frontier variables (output gap, price inflation, and wage inflation), the variance of the remaining two must be strictly positive. As we show below, if any one of the three policy-frontier variables is stabilized, the real wage must adjust in response to shocks. If one of the two inflation rates is stabilized, then the real wage must lie on either the household's or firm's real wage schedule (depending on which inflation rate is stabilized). In this situation the inflation rate that is not stabilized depends only on the output gap (and its own expected future value). Thus, stabilizing any two of the three variables is impossible because it precludes any adjustment in the real wage.

Our analysis has two general implications. First, if either of the nominal variables is completely stabilized, the adjustment process is the same irrespective of whether that variable is sticky or not. For example, if price inflation is stabilized, adjustment is the same when both prices and wages are sticky as when only wages are sticky. Second, the consequences of stabilizing a nominal variable depend critically on whether the nominal variable not being stabilized is sticky. For example, strict price inflation

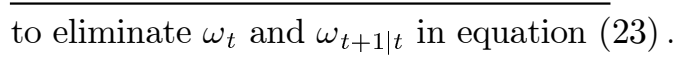


targeting can stabilize both price inflation and the output gap in the special case in which only prices are sticky because the real wage can change without requiring output to deviate from potential. However, if wages are sticky, the real wage can change only if the output gap changes.

\section{The Policy Frontier in a Tractable Version}

In the previous section, we demonstrated that the supply block of the model imposes certain restrictions on the policy frontier, by ruling out the possibility of completely stabilizing certain combinations of variables. In this section, we provide a complete characterization of the policy frontier for an analytically tractable version of the model, including conditions for the existence of a unique stationary rational expectations equilibrium (henceforth referred to as determinacy ). This exercise also illustrates the procedure used to calculate policy frontiers in more complicated models such as the one considered in Section 5. In this version of the model, wages are sticky but prices are perfectly flexible and the marginal product of labor is constant $(\alpha=0)$. This version comprises four equations: the wage setting equation (23), the price setting equation (A.4), the goods demand equation (T1.1), and the monetary rule $(T 1.8)$.

\subsection{Conditions for Determinacy of Equilibrium}

Sufficient conditions for the determinacy of equilibrium are given in Proposition 4:

Proposition 4: With sticky wages and flexible prices $\left(\xi_{W}>0, \xi_{P}=0\right)$ and a constant marginal product of labor $(\alpha=0)$, assume that $\gamma_{g} \geq 0, \gamma_{\pi} \geq 0$, and $\gamma_{\omega} \geq 0$. Then each of the following conditions is sufficient to ensure the existence of a unique, stationary rational expectations equilibrium:
(a) $\gamma_{\pi}>1$
(b) $\gamma_{\omega}>1$
(c) $\gamma_{g}>\left(\frac{\lambda_{W}}{1-\beta}\right)\left(1-\gamma_{\pi}-\gamma_{\omega}\right)$
(d) $\left(\frac{1-\beta}{\lambda_{W}}\right) \gamma_{g}+\gamma_{\pi}+\gamma_{\omega}-1>0$

Proof: See Appendix A.

The first two conditions are no doubt familiar to many. These conditions imply determinacy, for example, if a percentage point increase in either price inflation or wage inflation leads to a larger increase in the nominal interest rate.

The third condition may be somewhat surprising. According to this condition, if the interest rate response to the output gap $\left(\gamma_{g}\right)$ is large enough, then equilibrium is determinate even if the monetary rule does not include a nominal anchor (that is, 
even if both $\gamma_{\pi}$ and $\gamma_{\omega}$ are zero). ${ }^{34}$ It should be emphasized that nominal stickiness is necessary for this result. If wages and prices are perfectly flexible (that is, if $\xi_{P}=\xi_{W}=0$ ), determinacy requires that monetary policy pursue a nominal anchor with a sufficient degree of aggressiveness (that is, $\gamma_{\pi}+\gamma_{\omega}>1$ ). Given an empirically plausible degree of nominal inertia, determinacy requires that $\gamma_{g}$ be about 8 in the absence of a nominal anchor $\left(\gamma_{\pi}=\gamma_{\omega}=0\right) .^{35}$

Analogous results can be obtained in all the versions of the general model considered in this paper. We conjecture that no-need-for-a-nominal-anchor results are a general feature of staggered contract models and models with other forms of persistent nominal stickiness (for example, convex costs of adjusting wages and prices). In contrast, with synchronized contracts, it has been shown that a nominal anchor is required for determinacy. ${ }^{36}$

\subsection{Characterizing the Policy Frontier}

In this subsection we characterize the policy frontier associated with i.i.d. productivity shocks. The policymaker's variance loss function, $\mathcal{L}$, is a weighted sum of variances of the output gap, price inflation, and wage inflation:

$$
\mathcal{L}=\frac{1}{2}\left[\mu_{g} \sigma_{g}^{2}+\mu_{\pi} \sigma_{\pi}^{2}+\mu_{\omega} \sigma_{\omega}^{2}\right]
$$

where $\mu_{g}+\mu_{\pi}+\mu_{\omega}=1$.

Each point on the policy frontier is derived by choosing the parameters of the monetary policy rule to minimize the policymaker's loss function for a particular set of weights. The monetary policy rule is of the form:

$$
i=\bar{\gamma}_{\omega} \omega_{t}+\gamma_{x} x_{t}+\gamma_{x_{-1}} x_{t-1},
$$

The particular form of the monetary policy rule (27) reflects the fact that the state space of the model includes only the current and lagged productivity shock. In general, the variables included in the optimal monetary policy rule must span the state space of the model, so as to allow interest rates to react to any variable that affects the economy. If the policy instrument is the interest rate, the rule must also include an appropriate endogenous variable with a coefficient that ensures determinacy. For this purpose we include wage inflation, $\omega_{t}$, with a coefficient, $\bar{\gamma}_{\omega}$, greater than unity. The variances that appear in the loss function can be expressed as functions of the parameters of the monetary policy rule and the economic model. ${ }^{37}$

Given i.i.d. productivity shocks, the expressions for the variances are

\footnotetext{
${ }^{34}$ Clarida, Gali, and Gertler (1997) call attention to the fact that increasing $\gamma_{g}$ reduces the size of $\gamma_{\pi}$ required for determinacy but do not point out that $\gamma_{\pi}$ (and in our model $\gamma_{\omega}$ ) could be zero. On the basis of their estimate of $\gamma_{g}$ and other parameters, they conclude that the condition for determinacy cannot be met if $\gamma_{\pi}$ is very far below unity.

${ }^{35}$ This value is calculated using the lower bound in Proposition 4(c) and the parameters displayed in Table 3 .

${ }^{36}$ See, for example, Henderson and Kim (1998).

${ }^{37}$ The reduced-form solutions for the variables are in Appendix A.
} 


$$
\begin{aligned}
\sigma_{g}^{2} & =\frac{1}{\kappa_{W}^{2} \kappa^{2}}\left[\sigma_{\omega}^{2}-2 \beta d^{2} \gamma_{x} \gamma_{x_{-1}}-2 \beta d e \gamma_{x_{-1}}^{2}-2 \beta d f \gamma_{x_{-1}}+\beta^{2} d^{2} \gamma_{x_{-1}}^{2}\right] \\
\sigma_{\pi}^{2} & =\sigma_{\omega}^{2}+2 d \gamma_{x_{-1}}-2 d \gamma_{x}-2 e \gamma_{x_{-1}}-2 f+2 \\
\sigma_{\omega}^{2} & =d^{2} \gamma_{x_{-1}}^{2}+d^{2} \gamma_{x}^{2}+2 d e \gamma_{x} \gamma_{x_{-1}}+e^{2} \gamma_{x_{-1}}^{2}+2 d f \gamma_{x}+2 e f \gamma_{x_{-1}}+f^{2}, \\
d & =\frac{-\lambda_{W}}{\sigma \bar{\ell}_{C}+\lambda_{W} \bar{\gamma}_{\omega}}, e=-d^{2}\left[1+\frac{(1+\beta) \sigma \bar{\ell}_{C}}{\lambda_{W}}\right], f=d\left[\frac{\left(\sigma \bar{\ell}_{C}-1\right)\left(\alpha+\chi \bar{\ell}_{L}\right)}{\Delta}\right] .
\end{aligned}
$$

where the variance of the productivity shock has been set equal to unity for convenience $\left(\sigma_{x}^{2}=1\right)$.

Proposition 5 gives the coefficients $\left(\hat{\gamma}_{x}, \hat{\gamma}_{x_{-1}}\right)$ of the monetary policy rule that minimizes the variance loss function. These coefficients are functions of the parameters of the loss function and the structural parameters of the model (including $\left.\bar{\gamma}_{\omega}\right)$

Proposition 5: In the version with sticky wages and flexible prices $\left(0<\kappa_{W}<\right.$ $\infty$ and $\left.\kappa_{P} \rightarrow \infty\right)$, a constant marginal product of labor $(\alpha=0)$, and i.i.d. productivity shocks with a variance of unity $\left(\sigma_{x}^{2}=1, \sigma_{u}^{2}=0, \sigma_{z}^{2}=0, \rho_{x}=0\right)$, the loss function (26) is minimized by adopting a rule of the form (27) with the loss-minimizing coefficients given by

$$
\begin{gathered}
\hat{\gamma}_{x}=\frac{\mu_{\pi}}{d\left(1+\frac{\mu_{g}}{\lambda_{W}}-\mu_{g}\right)}-\frac{f}{d}+\left(\frac{\frac{\mu_{g} \beta}{\lambda_{W}}}{1+\frac{\mu_{g}}{\lambda_{W}}-\mu_{g}}-\frac{e}{d}\right) \hat{\gamma}_{x_{-1}}, \\
\hat{\gamma}_{x_{-1}}=\frac{-\mu_{\pi}\left(1+\frac{\mu_{g}}{\lambda_{W}}-\mu_{g}-\frac{\mu_{g} \beta}{\lambda_{W}}\right)}{d\left[\left(1+\frac{\mu_{g}}{\lambda_{W}}-\mu_{g}\right)^{2}+\frac{\mu_{g} \beta}{\lambda_{W}}\left(1-\mu_{g}\right)\right]} .
\end{gathered}
$$

The optimal variances are given by the variance expressions in equation (28) with $\gamma_{x}=\hat{\gamma}_{x}$ and $\gamma_{x_{-1}}=\hat{\gamma}_{x_{-1}}$.

Proof: See Appendix A

Proposition 5 shows that the variances of the output gap, price inflation, and wage inflation implied by minimizing the variance loss function (26) depend on the weights in the loss function. Varying the weights over all admissable values traces out a threedimensional policy frontier.

Two points on the frontier are particularly interesting and are easy to determine analytically. First, if only the variance of the output gap enters the loss function (26), that is, if $\mu_{g}=1$, then the variance expressions (28) imply that $\sigma_{\omega}^{2}=\sigma_{g}^{2}=0$ and that $\sigma_{\pi}^{2}=\operatorname{var}\left(x_{t}-x_{t-1}\right)=2 \sigma_{x}^{2}=2$, so that the variance of inflation simply equals twice the variance of the technology shock. ${ }^{38}$ With flexible prices, the real

\footnotetext{
${ }^{38}$ Recall that we assume for simplicity that $\sigma_{x}^{2}=1$.
} 
wage must equal the demand real wage, and with $\alpha=0$, the demand real wage must equal the productivity shock. Therefore, a positive productivity shock raises the real wage by an equal amount. If the output gap is completely stabilized, then nominal wage inflation remains constant and all real wage adjustment must be accomplished through price inflation.

Second, if only the variance of price inflation enters the variance loss function, that is, if $\mu_{\pi}=1$, then the variance expressions (28) imply that $\sigma_{\pi}^{2}=0$, that

$\sigma_{\omega}^{2}=\operatorname{var}\left(x_{t}-x_{t-1}\right)=2 \sigma_{x}^{2}=2$, and that $\sigma_{g}^{2}=\frac{1}{\kappa_{W}^{2} \kappa^{2}} \operatorname{var}\left(x_{t}-x_{t-1}\right)=\frac{2}{\kappa_{W}^{2} \kappa^{2}}$. The variance of the output gap with complete inflation stabilization is inversely related to the composite parameter $\lambda_{W}$, the parameter in the wage setting equation that determines the response of wage inflation to an increase in the output gap. If there is a positive productivity shock and price inflation is completely stabilized, all the required upward adjustment must be accomplished through wage inflation. If nominal wages are relatively sticky (that is, if $\lambda_{W}$ is small), then inflation stabilization induces relatively high output volatility, because the required change in wage inflation must be associated with a large increase in the output gap.

Figure 3 plots two-dimensional representations of the policy frontiers for wage contracts with average durations of 1.1 quarters (upper panels) and 2 quarters (lower panels). As shown in the left-hand panels, the amount of output volatility associated with complete inflation stabilization rises dramatically as wages become more sticky, that is, as the average duration of wage contracts increases. This version of the model is admittedly extreme because it forces the deflationary effects of a positive productivity shock to be offset exclusively through wage adjustment, whereas with a diminishing marginal product of labor, such a shock puts upward pressure on price inflation. ${ }^{39}$ Nevertheless, this diagram highlights the point that inflation stabilization can generate very large movements in the output gap.

\subsection{A Graphical Illustration}

In the case of i.i.d. shocks it is possible to illustrate graphically the results of the version with sticky wages, flexible prices, $\alpha=0$, and i.i.d. shocks. A key property of this version of the sticky wage model is that the price setting relation is not a one-to-one relationship between price inflation and the output gap. It is shown that in this version a variance tradeoff exists for productivity shocks but not for the other shocks.

According to Proposition 5, in this version if either the sum of $\gamma_{\pi}$ and $\gamma_{\omega}$ or $\gamma_{g}$ is large enough, the model has a unique equilibrium. All variables except price inflation with a productivity shock are expected to return to their steady state values in the period after any shock, and price inflation with a productivity shock is expected to return two periods after. That is, we obtain the surprising result that despite the fact that wages are set in staggered contracts, i.i.d. shocks do not have persistent effects. The explanation for this result is that with perfectly flexible prices the real wage can be at the value it would have with complete flexibility in the absence of a

\footnotetext{
${ }^{39} \mathrm{~A}$ version with decreasing returns is considered in Section 5.
} 
shock, and households do not care about the relative wages of the differentiated labor inputs that make up labor as long as they can supply the complete flexibility amount of labor.

This version of the model comprises equations (23), (A.4), (T1.1), and (T1.8) with $\gamma_{x}=\gamma_{x_{-1}}=0 . \omega_{t+1 \mid t}, y_{t+1 \mid t}$, and $y_{t+1 \mid t}^{*}$, and $u_{t+1 t}$ take on are at their steady state values of zero, and $\pi_{t+1 \mid t}=x_{t}$. Using equation (23) to eliminate $\omega_{t}$ wherever it appears yields the version of the model that will be used in the analysis:

$$
\begin{gathered}
\pi_{t}=\lambda_{W} g_{t}-x_{t}+x_{t-1}, \\
g_{t}=-\frac{1}{\sigma \bar{\ell}_{C}} i_{t}+\frac{1}{\sigma \bar{\ell}_{C}} x_{t}+\frac{\bar{\ell}_{U}}{\bar{\ell}_{C}} u_{t}-y_{t}^{*}, \\
i_{t}=\gamma_{\pi} \pi_{t}+\left(\gamma_{\omega} \lambda_{W}+\gamma_{g}\right) g_{t},
\end{gathered}
$$

where $y_{t}^{*}$ is defined in Table 1 .

This model can be analyzed using three schedules as shown in Figure 4. The upward sloping $A S$ schedule shows the pairs of price inflation and the output gap that satisfy the price setting equation (30). It bears repeating that a key property of this version of the sticky wage model is that the price setting relation is not a oneto-one relationship between price inflation and the output gap. In graphical terms, the productivity shock shifts the $A S$ schedule. The vertical $G$ schedule shows the value of $g_{t}$ which satisfies the goods demand equation (31) for a given interest rate. Increases in the interest rate shift the $G$ schedule to the left. The downward-sloping $R$ schedule shows the values of price inflation and the output gap which satisfy the policy rule, equation (32), for a given inflation rate, and increases in $i_{t}$ shift the $R$ schedule to the right.

As an example, consider the effects of a positive productivity shock with $\gamma_{g}, \gamma_{\omega}$, and $\gamma_{\pi}$ all finite so that the gap, wage inflation, and price inflation can deviate from their steady state values. These effects are shown in Figure 4.

We begin by considering the initial effects. One initial effect of the shock is familiar. The shock shifts the $A S$ schedule down from $A S_{0}$ to $A S_{1}$. For a given value of the gap (and therefore wage inflation), price inflation must be lower so that the real wage can rise. Another initial effect is less familiar. The shock shifts the $G$ schedule to the right from $G_{0}$ to $G_{1}$. An increase in $x_{t}$ raises expected inflation thereby raising the demand for output, and this effect outweighs the effect of the increase in $y_{t}^{*}$ which tends to lower the gap. In summary, when both initial effects are considered, at an unchanged interest rate, the shock increases the gap but may lower or raise price inflation.

Whether the interest rate rises or falls depends on whether the intersection of the $A S_{1}$ and $G_{1}$ schedules lies to the right or to the left of initial $R$ schedule. If it lies to the right as in Figure 4, the interest rate rises and the $G$ shift to the left and the $R$ schedule shifts to the right until they meet somewhere on the hatched portion of the shifted $A S$ schedule. In the new equilibrium, the output gap is definitely higher but 
price inflation may be higher or lower. If it lies to the left (not shown), the interest rate falls, the output gap is higher, and price inflation is definitely lower.

Now consider the extreme case shown in Figure 5. If approaches $\gamma_{g}$ or $\gamma_{\omega}$ approaches infinity but $\gamma_{\pi}$ does not, the $R$ schedule is vertical and shifts hardly at all when the interest rate changes.. The initial effects of the productivity shock are the same. The $A S_{1}$ and $G_{1}$ schedules intersect to the right of the original $R$ schedule so the interest rate rises. Since changes in the interest rate have hardly any effect on the $R$ schedule, the interest rate must rise by enough to shift the $G$ schedule back to $G_{0}$, so in this extreme case the positive productivity shock has no effect on the output gap but lowers inflation.

Next note that the initial effect of a positive consumption shock shifts the $G$ schedule to the right from $G_{0}$ to $G_{1}$ but has no effect on the $A S$ schedule. The rest of the analysis of consumption shocks is analogous to the analysis of productivity shocks. When $\gamma_{g}, \gamma_{\omega}$, and $\gamma_{\pi}$ are finite the consumption shock raises both the output gap and price inflation, and in the extreme case in which $\gamma_{g}$ or $\gamma_{\omega}$ approaches infinity but $\gamma_{\pi}$ does not, the consumption shock has no effect on either variable.

Finally consider the two extreme cases shown in Figure 6. As in Figure 4, the vertical $R$ schedule represents the extreme case in which $\gamma_{g}$ or $\gamma_{\omega}$ approaches infinity but $\gamma_{\pi}$ does not. The horizontal $R$ schedule represents the other extreme case in which $\gamma_{\pi}$ approaches infinity but $\gamma_{g}$ and $\gamma_{\omega}$ do not. In both extreme cases, the $R$ schedule shifts hardly at all when the interest rate changes. Productivity shocks shift the $A S$ schedule, but the other shocks do not. Movements in the interest rate always shift the $G$ schedule until it passes through the intersection of the virtually unshifted $R$ schedule and the $A S$ schedule whether it has shifted or not. Therefore, in this version of the sticky wage model, for productivity shocks stabilizing the output gap and wage inflation, that is, making $R$ vertical, does not stabilize price inflation and stabilizing price inflation, that is, making $R$ horizontal, does not stabilize the output gap and wage inflation. For other shocks stabilizing either the output gap, wage inflation, or price inflation stabilizes all three. Therefore, in this version there is a tradeoff between output-gap and price-inflation variances for productivity shocks but not for other shocks.

\section{$5 \quad$ The Policy Frontier in the General Model}

Proposition 3 above establishes that supply block considerations alone imply that when both wages and prices are sticky, it is not feasible to completely stabilize more than one of the following three variables: the output gap, price inflation, and wage inflation. In this section, we find monetary policy rules that generate the points on the policy frontier at which the variance of one of the variables is equal to zero. We also employ numerical methods to calculate policy frontiers using reasonably standard parameter values. 


\subsection{Analytical Results}

In this subsection, we present three propositions about complete stabilization of the output gap, price inflation, and wage inflation, respectively. Table 2 contains several expressions used in formulating these propositions. The solutions for three variables in the complete flexibility version of the model - the real interest rate $\left(r_{t}^{*}\right)$, output, and the real wage - are given in equations (T2.1) through (T2.3). The expressions for the $f_{j}$ and $k_{j}$ come from (T1.9) and (T1.10).

The expressions for the variances of the real wage, the output gap, wage inflation, and price inflation have the same form no matter which of the latter three variables is stabilized, but these expressions have different coefficient values depending on which variable is stabilized. The general expressions for the variances are

$$
\begin{gathered}
\sigma_{\zeta}^{2}=\sum_{j=u, x, z}\left(\frac{1+a_{0} \rho_{j}}{1-a_{0} \rho_{j}}\right)\left(\frac{a_{j}^{2}}{1-a_{0}^{2}}\right) \sigma_{j}^{2} \\
\sigma_{i}^{2}=\sum_{j=u, x, z}\left[\left(\frac{1+a_{0} \rho_{j}}{1-a_{0} \rho_{j}}\right)\left(\frac{c_{i 0}^{2} a_{j}^{2}}{1-a_{0}^{2}}\right)+\left(\frac{2 a_{j} c_{i j} \rho_{j} c_{i 0}}{1-a_{0} \rho_{j}}\right)+c_{i j}^{2}\right], \quad i=\omega, g, \pi
\end{gathered}
$$

The coefficients $q, a_{j}, c_{g j}, c_{\pi j}$, and $c_{\omega j}$ are the coefficients of the solutions for the real wage, the output gap, price inflation and wage inflation that are written in general terms in Table 2. These coefficients take on different values depending on which variable is being stabilized.

Proposition 6: (Output-gap) With sticky wages and sticky prices $\left(\xi_{W}>0, \xi_{P}>0\right)$, for the policy rule

$$
i_{t}=r_{t}^{*}+\pi_{t+1 \mid t}+\gamma_{g} g_{t}
$$

there is a unique, stationary rational expectations equilibrium in which $\sigma_{g}^{2}=0$, and $\sigma_{\pi}^{2}$ and $\sigma_{\omega}^{2}$ are given by equation $(33), q=\frac{\kappa_{W}+\kappa_{P}}{2 \beta}$, and the $c_{i j}$ are given by

$$
\begin{gathered}
c_{\omega 0}=\frac{\kappa_{W} a_{0}}{1-\beta a_{0}}, c_{\omega j}=\frac{\kappa_{W} k_{j}-\left(\kappa_{W}-\beta c_{\omega 0}\right) a_{j}}{1-\beta \rho_{j}}, \\
c_{\pi 0}=\frac{\kappa_{P} a_{0}}{1-\beta a_{0}}, c_{\pi j}=\frac{\left(\kappa_{P}+\beta c_{\pi 0}\right) a_{j}-\kappa_{P} k_{j}}{1-\beta \rho_{j}}, \quad j=u, x, z,
\end{gathered}
$$

Proof: See Appendix A.

We know from Proposition 3 that in the general model when $\sigma_{g}^{2}=0$, the variances $\sigma_{\pi}^{2}$ and $\sigma_{\omega}^{2}$ are strictly positive. However, in accord with Proposition 1 , if $\xi_{W}=0$ for fixed $\xi_{P}, \sigma_{\pi}^{2}=0$. If $\xi_{W}=0, \kappa_{W} \rightarrow \infty, a_{0} \rightarrow 0, c_{\pi 0} \rightarrow 0$, and $a_{j} \rightarrow k_{j}$ and $c_{\pi u} \rightarrow 0$

for $j=u, x, z$. Also, in accord with Proposition 2, if $\xi_{P}=0$ for fixed $\xi_{W}$, then $\sigma_{\omega}^{2}=0$. If $\xi_{P}=0, \kappa_{P} \rightarrow \infty, c_{\omega 0} \rightarrow 0$, and $c_{\omega j} \rightarrow 0, j=u, x, z$. 


\section{Table 2: Expressions for Analysis of the General Model}

\section{Complete Flexibility}

$$
\begin{array}{ll}
r_{t}^{*}=\sigma \bar{\ell}_{C}\left(y_{t+1 \mid t}^{*}-y_{t}^{*}\right)+\bar{\ell}_{U}\left(u_{t}-u_{t+1 \mid t}\right) & \text { real interest rate } \\
y_{t}^{*}=f_{u} u_{t}+f_{x} x_{t}+f_{z} z_{t}, & \text { output } \\
f_{u}=\frac{(1-\alpha) \sigma \bar{\ell}_{U}}{\Delta}, f_{x}=\frac{1+\chi \bar{\ell}_{L}}{\Delta}, f_{z}=\frac{(\alpha-1) \chi \bar{\ell}_{Z}}{\Delta}, & \\
\zeta_{t}^{*}=k_{u} u_{t}+k_{x} x_{t}+k_{z} z_{t}, & \text { real wage } \\
k_{u}=-\frac{\alpha \sigma \bar{\ell}_{U}}{\Delta}, k_{x}=\frac{\chi \bar{\ell}_{L}+\sigma \bar{\ell}_{C}}{\Delta}, k_{z}=\frac{\alpha \chi \bar{\ell}_{L}}{\Delta}, &
\end{array}
$$

\section{Solutions}

$$
\begin{array}{ll}
\zeta_{t}=a_{0} \zeta_{t-1}+a_{u} u_{t}+a_{x} x_{t}+a_{z} z_{t}, & \text { real wage } \\
a_{0}(q)=1+\frac{1-\beta}{2 \beta}+q-\sqrt{\left(1+\frac{1-\beta}{2 \beta}+q\right)^{2}-\frac{1}{\beta}} & \text { real wage coefficient } \\
a_{j}(q)=\frac{q k_{j}}{1+\frac{1-\beta}{2 \beta}+q-\frac{1}{2}\left[a_{0}(q)+\rho_{j}\right]}, \quad j=u, x, z, & \text { real wage coefficient } \\
g_{t}=c_{g 0} \zeta_{t-1}+c_{g u} u_{t}+c_{g x} x_{t}+c_{g z} z_{t}, & \text { output gap } \\
\pi_{t}=c_{\pi 0} \zeta_{t-1}+c_{\pi u} u_{t}+c_{\pi x} x_{t}+c_{\pi z} z_{t}, & \text { price inflation } \\
\omega_{t}=c_{\omega 0} \zeta_{t-1}+c_{\omega u} u_{t}+c_{\omega x} x_{t}+c_{\omega z} z_{t} . & \text { wage inflation }
\end{array}
$$

Proposition 7: (Price Inflation) In the sticky wage and price version $\left(\xi_{W}>0, \xi_{P}>0\right)$, for the policy rule

$$
i_{t}=r_{t}^{*}+\sigma \bar{\ell}_{C}\left(g_{t+1 \mid t}-g_{t}\right)+\gamma_{\pi} \pi_{t},
$$

there is a unique stationary rational expectations equilibrium in which $\sigma_{\pi}^{2}=0$, and $\sigma_{g}^{2}$ and $\sigma_{\omega}^{2}$ are given by (33), $q=\frac{\kappa_{W} \Delta}{2 \alpha \beta}$, and the $c_{i j}$ are given by

$$
\begin{gathered}
c_{\omega 0}=a_{0}-1, \quad c_{\omega j}=a_{j}, \quad j=u, x, z \\
c_{g 0}=\frac{(\alpha-1) a_{0}}{\alpha}, \quad c_{g u}=\frac{(\alpha-1) a_{u}-\alpha f_{u}}{\alpha}, \\
c_{g x}=\frac{\left[(\alpha-1) a_{x}-\alpha f_{x}+1\right]}{\alpha} \quad c_{g z}=\frac{(\alpha-1) a_{z}-\alpha f_{z}}{\alpha}
\end{gathered}
$$


Proof: See Appendix A.

In accord with Proposition 1 , if $\xi_{W}=0$ for fixed $\xi_{P}, \sigma_{\zeta}^{2}=\sigma_{\zeta^{*}}^{2}$ and $\sigma_{g}^{2}=0$. If $\xi_{W}=0, \kappa_{W} \rightarrow \infty, a_{0} \rightarrow 0$, and $a_{j} \rightarrow k_{j}, j=u, x, z$. It follows that $c_{g 0} \rightarrow 0$ and $c_{g j} \rightarrow 0, j=u, x, z$. Thus, $\sigma_{\zeta}^{2}=\sigma_{\zeta^{*}}^{2}$ and $\sigma_{g}^{2} \rightarrow 0$.

Proposition 8: (Wage Inflation) In the sticky wage and price version $\left(\xi_{W}>0, \xi_{P}>0\right)$, for the policy rule

$$
i_{t}=r_{t}^{*}+\sigma \bar{\ell}_{C}\left(g_{t+1 \mid t}-g_{t}\right)+\zeta_{t}-\zeta_{t+1 \mid t}+\gamma_{\omega} \omega_{t}
$$

there is a unique stationary rational expectations equilibrium in which $\sigma_{\omega}^{2}=0$, and $\sigma_{g}^{2}$ and $\sigma_{\pi}^{2}$ are given by $(33), q=\frac{\kappa_{P} \Delta}{2 \beta(\Delta-\alpha)}$, and the $c_{i j}$ are given by

$$
\begin{gathered}
c_{\pi 0}=1-a_{0}, \quad c_{\pi j}=-a_{j}, \quad j=u, x, z . \\
c_{g 0}=\frac{(1-\alpha) a_{0}}{\Delta-\alpha}, \quad c_{g u}=\frac{(1-\alpha) a_{u}+\alpha f_{u}}{\Delta-\alpha}, \\
c_{g x}=\frac{(1-\alpha) a_{x}+\alpha f_{x}-1}{\Delta-\alpha}, \quad c_{g z}=\frac{(1-\alpha) a_{z}+\alpha f_{z}}{\Delta-\alpha}
\end{gathered}
$$

Proof: See Appendix A.

In accord with Propositions 2 , if $\xi_{P}=0$ for fixed $\xi_{W}, \sigma_{\zeta}^{2}=\sigma_{\zeta^{*}}^{2}$ and $\sigma_{g}^{2}=0$. If $\xi_{P}=0, \kappa_{P} \rightarrow \infty, a_{0} \rightarrow 0$, and $a_{j} \rightarrow k_{i}, j=u, x, z$. It follows that $c_{g 0} \rightarrow 0$ and $c_{g j} \rightarrow 0, j=u, x, z$. Thus, $\sigma_{\zeta}^{2}=\sigma_{\zeta^{*}}^{2}$ and $\sigma_{g}^{2} \rightarrow 0$.

\subsection{Numerical Results}

While the previous subsection provided analytical expressions for boundary points of the monetary policy frontier, numerical methods are required to investigate other properties such as the slope of the policy frontier at intermediate points. Thus, we calibrate the general model using reasonably standard parameter values, and then we follow the approach of Williams (1997) and Levin, Wieland, and Williams (1998) to compute the policy frontier.

Table 3 reports the values of the structural parameters used here. In particular, we assume that output has a labor elasticity of 0.7 (not the labor elasticity of unity that was assumed in Section 4). Furthermore, price contracts have an average duration of two quarters, while wage contracts have an average duration of four quarters. Rather than making specific assumptions about the contemporaneous correlations between the disturbances, we calculate a separate policy frontier for each of the three shocks $\left(u_{t}, x_{t}\right.$, and $\left.z_{t}\right)$. In computing each frontier, we scale the variance of the shock so that potential output has unit variance. 


\begin{tabular}{|llll|}
\hline Table 3: The Parameters of the Model of Table 1 \\
$\theta_{W}=\theta_{P}=.75$ & $\alpha=.3$ & $\rho_{u}=.5$ & $\bar{Y}=1$ \\
$\xi_{P}=.5$ & $\bar{\ell}_{C}=1.11$ & $\rho_{x}=.95$ & $\bar{C}=1$ \\
$\xi_{W}=.75$ & $\bar{\ell}_{U}=0.11$ & $\rho_{z}=.5$ & $\bar{U}=.1$ \\
$\beta=.99$ & $\bar{\ell}_{Z}=0.043$ & $\kappa_{P}=.51$ & $\bar{L}=.27$ \\
$\sigma=1.5$ & $\bar{\ell}_{L}=.37$ & $\kappa_{W}=.027$ & $\bar{Z}=.03$ \\
$\chi=1.5$ & $\Delta=2.02$ & $\kappa=2.89$ & \\
\hline
\end{tabular}

For each shock, we consider policy rules in which the current interest rate responds to $\pi_{t}, \zeta_{t-1}$, and the current and lagged values of the shock. ${ }^{40}$ The coefficient on $\pi_{t}$ is set equal to 2 , while the other three parameters of the interest rate rule are chosen to minimize the loss function given in equation (26) for given weights $\mu_{\pi}$ and $\mu_{g}$. For any interest rate rule in this class, the model yields a determinate solution, and the reduced-form equation for each endogenous variable (including $\pi_{t}$ ) can be expressed in terms of $\zeta_{t-1}$ and the current and lagged values of the shock. ${ }^{41}$ Thus, for given loss function weights $\mu_{\pi}$ and $\mu_{g}$, this class of interest rate rules always encompasses the optimal policy rule.

For a given set of parameters of the interest rate rule, we confirm the determinacy conditions and compute the reduced-form solution of the model using the numerical algorithm of Anderson and Moore (1985), which provides an efficient implementation of the method proposed by Blanchard and Kahn (1980). ${ }^{42}$ Given the reduced-form representation, it is straightforward to calculate the unconditional second moments of the endogenous variables. Finally, we use the Newton-Raphson method to find the policy rule parameters that minimize the loss function for given values of $\mu_{\pi}$ and $\mu_{g}$. By varying these weights over the unit circle, we trace out the three-dimensional policy frontier describing the set of efficient outcomes for the variances of price inflation, wage inflation, and the output gap.

Figure 7 presents three two-dimensional views of the policy frontier corresponding to productivity shocks, while the upper panels of Figure 8 give two-dimensional views of the policy frontier associated with consumption demand shocks, and the lower

${ }^{40}$ Note that this class of interest rate rules is somewhat broader than that given in equation $(T 1.8)$.

${ }^{41}$ This result follows from the fact that the general model can be expressed (after various substitutions) as a fourth-order difference equation in the real wage, with three leads and one lag. Determinacy is ensured if the interest rate rule yields three roots outside the unit circle and one root inside the unit circle.

${ }^{42} \mathrm{~A}$ detailed description of the algorithm and recent enhancements may be found in Anderson (1997). Using Matlab version 5.2 on a $266 \mathrm{Mhz}$ Pentium, this algorithm generates the rational expectations solution within a few seconds for every case considered here. 
panels of Figure 8 give similar views for the policy frontier associated with labor supply shocks. In response to all three shocks, strict inflation targeting $\left(\mu_{\pi}=1\right)$ can completely stabilize inflation, while generating output gap variance of about 0.5 to 0.9 and wage inflation variance of about 0.005 to $0.03 .{ }^{43}$

The cost (in terms of output variability) of stabilizing inflation is lower with diminishing returns to labor than with a constant marginal product of labor. With diminishing returns $(\alpha>0)$, equation (A.4) indicates that an expansion in the output gap has a direct effect on price inflation in addition to an indirect effect operating through increased wage inflation. This direct effect helps to account for the fact that the variance of output associated with inflation targeting in Figure 7 is much lower than in the lower panel of Figure 3, even though the average duration of wage contracts is twice as large.

Nevertheless, Figures 7 and 8 depict very flat variance tradeoffs. Inflation targeting is a very costly strategy in the sense that output gap volatility can be drastically reduced without inducing much variation in price inflation. Furthermore, these figures exhibit relatively small tradeoffs between output gap volatility and wage inflation volatility: for a given amount of price inflation variance, policy rules chosen to minimize wage inflation variance (i.e., rules associated with $\mu_{\omega}=1-\mu_{\pi}$ ) yield only slightly higher output gap volatility than rules chosen to minimize output gap variance (i.e., rules associated with $\left.\mu_{g}=1-\mu_{\pi}\right)$. Thus, when both wages and prices exhibit an empirically reasonable degree of nominal inertia, strict price inflation targeting would be chosen only by policymakers who place a very low relative weight on output-gap variability.

\section{Conclusions}

In this paper, we have utilized a simple model with optimizing agents that incorporates both wage and price rigidities. We have demonstrated the existence of a monetary policy tradeoff between price-inflation variability and output-gap variability. This variance tradeoff is absent only in the special case in which prices are sticky and wages are perfectly flexible. In general, it is infeasible to stabilize more than one of the following three variables: the output gap, price inflation, and wage inflation.

Our results highlight the need for further research on criteria for policy evaluation and on the empirical relevance of different types of nominal rigidity. We have derived monetary policy frontiers subject to the weak restriction that policymaker loss is increasing in the variances of the output gap, price inflation, and wage inflation volatility. Nevertheless, the variance of nominal interest rates may also be of concern to policymakers. More can be learned from comparisons of alternative monetary policy rules using particular parameterizations of the policymaker loss function and, especially, from extensions of existing research on the relationship between the utility functions of private agents and policymaker loss functions.

\footnotetext{
${ }^{43}$ All the tradeoff curves are derived conditional on shocks that are scaled so that the variance of potential output is one percent. Thus, the variance of the output gap conditional on an inflation targeting strategy and the variance of potential output are of the same order of magnitude.
} 
We have demonstrated that conclusions about optimal monetary policy are sensitive to assumptions about nominal rigidities. Strict inflation targeting has appealing welfare implications in models in which only prices are sticky. However, when our model is calibrated to exhibit an empirically reasonable degree of nominal wage inertia, strict inflation targeting induces substantial output-gap volatility. Accordingly, our results underline the importance of the ongoing task of quantifying the degrees of nominal wage and price rigidity. 


\section{Appendix A}

This Appendix contains the proofs of Propositions $1-6$.

\section{Proof of Proposition 1}

If $\xi_{P}>0$ and $\xi_{W}=0$, then the supply block can be reduced to the following two equations:

$$
\begin{aligned}
\pi_{t}=\beta & \pi_{t+1 \mid t}+\lambda_{P} g_{t}, \\
\omega_{t}-\pi_{t}= & \ell\left[\left(g_{t}-g_{t-1}\right)+\left(y_{t}^{*}-y_{t-1}^{*}\right)\right] \\
& -\frac{\chi \bar{\ell}_{L}}{1-\alpha}\left(x_{t}-x_{t-1}\right)-\sigma \bar{\ell}_{U}\left(u_{t}-u_{t-1}\right)+\chi \bar{\ell}_{Z}\left(z_{t}-z_{t-1}\right) .
\end{aligned}
$$

If $\sigma_{\pi}^{2}=0$, then equation $(A .1)$ implies that $\sigma_{g}^{2}=0$ and then equation $(A .2)$ implies $\sigma_{\omega}^{2}>0$. If $\sigma_{g}^{2}=0$ and $\lim \pi_{t+1 \mid t} \rightarrow 0$, then equation $(A .1)$ implies that $\sigma_{\pi}^{2}=0$ and then equation $(A .2)$ implies $\sigma_{\omega}^{2}>0$. Now assume $\sigma_{\pi}^{2}=\sigma_{g}^{2}=0$ and suppose that $\sigma_{\omega}^{2}=0$, or assume $\sigma_{\omega}^{2}=0$, and suppose $\sigma_{\pi}^{2}=\sigma_{g}^{2}=0$. Either of these suppositions generates a contradiction because the variance of the right hand side of equation $(A .2)$ is positive. Therefore, it must be that $\sigma_{\pi}^{2}=\sigma_{g}^{2}=0 \rightarrow \sigma_{\omega}^{2}>0$, and $\sigma_{\omega}^{2}=0 \rightarrow \sigma_{\pi}^{2}>$ $0, \sigma_{g}^{2}>0$.

\section{Proof of Proposition 2}

If $\xi_{W}>0$ and $\xi_{p}=0$, then the supply block can be reduced to the following two equations:

$$
\begin{gathered}
\omega_{t}=\beta \omega_{t+1 \mid t}+\lambda_{W} g_{t}, \\
\pi_{t}-\omega_{t}=\left(\frac{\alpha}{1-\alpha}\right)\left[\left(g_{t}-g_{t-1}\right)+\left(y_{t}^{*}-y_{t-1}^{*}\right)\right]-\left(\frac{1}{1-\alpha}\right)\left(x_{t}-x_{t-1}\right) .
\end{gathered}
$$

If $\sigma_{\omega}^{2}=0$, then equation (A.3) implies that $\sigma_{g}^{2}=0$ and then equation $(A .4)$ implies $\sigma_{\pi}^{2}>0$. If $\sigma_{g}^{2}=0$ and $\lim \pi_{\omega+1 \mid t} \rightarrow 0$, then equation $(A .3)$ implies that $\sigma_{\omega}^{2}=0$ and then equation $(A .4)$ implies $\sigma_{\pi}^{2}>0$. Now assume $\sigma_{\omega}^{2}=\sigma_{g}^{2}=0$ and suppose $\operatorname{var}(\pi)=0$, or assume $\operatorname{var}(\pi)=0$, and suppose $\sigma_{\omega}^{2}=0$. Either of these suppositions generates a contradiction because the variance of the right hand side of equation (A.4) is positive. Therefore, it must be that $\sigma_{\omega}^{2}=\sigma_{g}^{2}=0 \rightarrow \operatorname{var}(\pi)>0$, and $\operatorname{var}(\pi)=0 \rightarrow \sigma_{\omega}^{2}>0, \sigma_{g}^{2}>0 . \operatorname{var}(\pi)>0$.

\section{Proof of Proposition 3}

According to equation $(A .5)$,

$$
\sigma_{g}^{2}=0 \Leftrightarrow \zeta_{t}^{s}=\zeta_{t}^{d}=\zeta_{t}^{*}
$$

Therefore, if $\sigma_{g}^{2}=0$, equations $(T 1.2)$ and (T1.4) imply that if $\sigma_{\omega}^{2}=0$, then $\sigma_{\pi}^{2}=0$ and vice versa. Also, if $\sigma_{\pi}^{2}=0$, equations $(T 1.2),(T 1.4)$, and $(A .5)$ imply that if $\sigma_{g}^{2}=0$, then $\sigma_{\omega}^{2}=0$ and vice versa. In addition, if $\sigma_{\omega}^{2}=0$, equations $(T 1.2),(T 1.4)$, and (A.5) imply that if $\sigma_{g}^{2}=0$, then $\sigma_{\pi}^{2}=0$ and vice versa. That is, if any two of $\sigma_{g}^{2}, \sigma_{\pi}^{2}$, and $\sigma_{\omega}^{2}$ are equal to zero third must also be equal to zero. Suppose that 
$\sigma_{g}^{2}=\sigma_{\pi}^{2}=\sigma_{\omega}^{2}=0$. This supposition generates a contradiction because the variance of the right hand side of equation $(A .6)$ is positive.

$$
\omega-\pi=-\frac{\alpha \sigma \bar{\ell}_{C}}{\Delta}\left(u_{t}-u_{t-1}\right)+\frac{\alpha \chi \bar{\ell}_{L}}{\Delta}\left(z_{t}-z_{t-1}\right)+\frac{\chi \bar{\ell}_{L}+\sigma \bar{\ell}_{C}}{\Delta}\left(x_{t}-x_{t-1}\right)
$$

Therefore, $\sigma_{g}^{2}=0 \rightarrow \sigma_{\pi}^{2}>0$ and $\sigma_{\omega}^{2}>0, \sigma_{\pi}^{2}=0 \rightarrow \sigma_{g}^{2}>0$ and $\sigma_{\omega}^{2}>0, \sigma_{\omega}^{2}=0 \rightarrow$ $\sigma_{g}^{2}>0$ and $\sigma_{\pi}^{2}>0$.

\section{Proof of Proposition 4}

The basic difference equations for the sticky wage version with $\alpha=0$ can be expressed as

$$
\mathbf{y}_{t+1}=\mathbf{A} \mathbf{y}_{t}+\mathbf{B} \mathbf{u}_{t}
$$

where

$$
\begin{aligned}
& \mathbf{y}_{t}=\left(\begin{array}{c}
\omega_{t} \\
g_{t}
\end{array}\right), \mathbf{A}=\left(\begin{array}{cc}
\frac{1}{\beta} & -\frac{k_{W} \kappa}{\beta} \\
\frac{\gamma_{\omega}+\gamma_{\pi}-\frac{1}{\beta}}{\sigma \ell_{C}} & 1+\frac{\gamma_{g}+\frac{k_{W} \kappa}{\beta}}{\sigma \ell_{C}}
\end{array}\right), \mathbf{u}_{t}=\left(\begin{array}{c}
u_{t} \\
z_{t} \\
x_{t} \\
x_{t-1}
\end{array}\right) \\
& \mathbf{B}=\left(\begin{array}{cccc}
0 & 0 & 0 & 0 \\
-\frac{\sigma \bar{\ell}_{U} \chi \bar{\ell}_{L}\left(1-\rho_{u}\right)}{\sigma \bar{\ell}_{C} \Delta_{4}} & -\frac{\chi \bar{\ell}_{Z}\left(1-\rho_{z}\right)}{\Delta_{4}} & \frac{\left(\sigma \bar{\ell}_{C}-1\right) \chi \bar{\ell}_{L}\left(1-\rho_{x}\right)}{\sigma \bar{\ell}_{C} \Delta_{4}}-\frac{\gamma_{\pi+} \gamma_{x}}{\sigma \bar{\ell}_{C}} & \frac{\gamma_{\pi}-\gamma_{x_{-1}}}{\sigma \bar{\ell}_{C}}
\end{array}\right) \\
& \Delta_{4}=\chi \bar{\ell}_{L}+\sigma \bar{\ell}_{C}
\end{aligned}
$$

The eigenvalues of $\mathbf{A}$ are

$$
\tau_{1,} \tau_{2}=1+\frac{1-\beta}{2 \beta}+\frac{\gamma_{g}+\frac{k_{W} \kappa}{\beta}}{2 \sigma \bar{\ell}_{C}} \pm \sqrt{\left(1+\frac{1-\beta}{2 \beta}+\frac{\gamma_{g}+\frac{k_{W} \kappa}{\beta}}{2 \sigma \bar{\ell}_{C}}\right)^{2}-\left(\frac{1}{\beta}+\frac{\gamma_{g}+k_{W} \kappa\left(\gamma_{\omega}+\gamma_{\pi}\right)}{\beta \sigma \bar{\ell}_{C}}\right)}
$$

where the + and - of \pm apply to $\tau_{1}$ and $\tau_{2}$, respectively. There are no initial conditions, so there is a unique stationary rational expectations equilibrium if the real parts of both of the eigenvalues of $\mathbf{A}$ exceed one in absolute value. Since $\beta<1$ and the expression under the radical can be written as

$$
\left(\frac{1-\beta}{2 \beta}+\frac{\gamma_{g}+\frac{k_{W} \kappa}{\beta}}{2 \sigma \bar{\ell}_{C}}\right)^{2}-\frac{k_{W} \kappa}{\beta 2 \sigma \bar{\ell}_{C}}\left[\left(\frac{1-\beta}{k_{W} \kappa}\right) \gamma_{g}+\gamma_{\omega}+\gamma_{\pi}-1\right]
$$

both roots are real and exceed positive one if real and both exceed positive one if $\gamma_{g}$ and $\left(\frac{1-\beta}{k_{P} \kappa}\right) \gamma_{g}+\gamma_{\pi}-1>0$.

The solutions for $\omega_{t}$ and $g_{t}$ can be expressed in matrix form

$$
\mathbf{y}_{t}=\mathbf{C u}_{t}
$$

where in this case 


$$
\begin{gathered}
\mathbf{C}=\left(\begin{array}{cccc}
\frac{a_{12} b_{21}}{\left(\tau_{1}-\rho_{u}\right)\left(\tau_{2}-\rho_{u}\right)} & \frac{a_{12} b_{22}}{\left(\tau_{1}-\rho_{z}\right)\left(\tau_{2}-\rho_{z}\right)} & \frac{a_{12}\left(\rho_{x} b_{23}+b_{24}\right)}{\left(\tau_{1}-\rho_{x}\right)\left(\tau_{2}-\rho_{x}\right) \rho_{x}}-\frac{a_{12} b_{24}}{\tau_{1} \tau_{2} \rho_{x}} & \frac{a_{12} b_{24}}{\tau_{1} \tau_{2}} \\
\frac{\left(\rho_{u}-a_{11}\right) b_{21}}{\left(\tau_{1}-\rho_{u}\right)\left(\tau_{2}-\rho_{u}\right)} & \frac{\left(\rho_{z}-a_{11}\right) b_{22}}{\left(\tau_{1}-\rho_{z}\right)\left(\tau_{2}-\rho_{z}\right)} & \frac{\left(\rho_{x}-a_{11}\right)\left(\rho_{x} b_{23}+b_{24}\right)}{\left(\tau_{1}-\rho_{x}\right)\left(\tau_{2}-\rho_{x}\right) \rho_{x}}+\frac{a_{11} b_{24}}{\tau_{1} \tau_{2} \rho_{x}} & -\frac{a_{11} b_{24}}{\tau_{1} \tau_{2}}
\end{array}\right) \\
\left(\tau_{1}-\rho_{j}\right)\left(\tau_{2}-\rho_{j}\right)=\tau_{1} \tau_{2}-\rho_{j}\left(\tau_{1}+\tau_{2}\right)+\rho_{j}^{2}, j=1, \ldots, 3 \\
\tau_{1} \tau_{2}=\frac{1}{\beta}\left(1+\frac{\gamma_{g}+k_{W} \kappa\left(\gamma_{\omega}+\gamma_{\pi}\right)}{\sigma \bar{\ell}_{C}}\right) \\
\tau_{1}+\tau_{2}=\frac{1}{\beta}+1+\frac{\gamma_{g}+\frac{k_{W} \kappa}{\beta}}{\sigma \bar{\ell}_{C}}
\end{gathered}
$$

and $b_{21}, b_{22}, b_{23}$, and $b_{24}$ make up the bottom row of the matrix $\mathbf{B}$ which is defined in equation (A.9).

The solution for $\pi_{t}$ is

$$
\pi_{t}=c_{11} u_{t}+c_{12} z_{t}+\left(c_{13}-1\right) x_{t}+\left(c_{14}+1\right) x_{t-1}
$$

All the elements of $\mathbf{C}$ have denominators of the same form which is given by equation (A.15). As can be seen from equations (A.16) and (A.17) this denominator rises without limit as $\gamma_{g}, \gamma_{\omega}$, or $\gamma_{\pi}$ rise without limit. Furthermore, as can be seen from equation (A.9) none of the elements of the matrix $\mathbf{B}$ depends $\gamma_{\omega}$ on or $\gamma_{g}$, but $b_{13}$ and $b_{14}$ rise without limit as $\gamma_{\pi}$ rises. Therefore, complete stabilization of either $g_{t}$ or $\omega_{t}\left(\gamma_{\omega}\right.$ or $\gamma_{g}$ approaches infinity with $\gamma_{\pi}$ finite $)$ reduces all the elements of $\mathbf{C}$ to zero, so the solution for $\pi_{t}$ reduces to

$$
\left.\pi_{t}\right|_{\gamma_{\omega} \text { or } \gamma_{g} \rightarrow \infty}=-x_{t}+x_{t-1} .
$$

In contrast, complete stabilization of $\pi_{t}\left(\gamma_{\pi}\right.$ approaches infinity with $\gamma_{g}$ and $\gamma_{\omega}$ finite) does not reduce $c_{13}$ and $c_{14}$ to zero, and the solutions for $\omega_{t}$ and $g_{t}$ are

$$
\begin{gathered}
\left.\omega_{t}\right|_{\gamma_{\pi} \rightarrow \infty}=x_{t}-x_{t-1} \\
\left.g_{t}\right|_{\gamma_{\pi} \rightarrow \infty}=\left(\frac{\beta\left(1-\rho_{x}\right)+1}{\lambda_{W}}\right) x_{t}-\left(\frac{1}{\lambda_{W}}\right) x_{t-1}
\end{gathered}
$$

\section{Proof of Proposition 5}

To evaluate the loss function (26), we use the variance expressions given in equation (33). The first-order conditions for a minimum of the loss function with respect to $\gamma_{x}$ and $\gamma_{x_{-1}}$ are

$$
\begin{gathered}
\frac{\partial \mathcal{L}}{\partial \gamma_{x_{-1}}}=\mu_{\pi}(d-e)+\frac{\mu_{g}\left(\beta^{2} d^{2}-2 \beta d e\right)}{\kappa_{W}^{2} \kappa^{2}} \gamma_{x_{-1}}-\frac{\mu_{g} \beta d^{2}}{\kappa_{W}^{2} \kappa^{2}} \gamma_{x}-\frac{\mu_{g} \beta d f}{\kappa_{W}^{2} \kappa^{2}} \\
+\left(1+\frac{\mu_{g}}{\kappa_{W}^{2} \kappa^{2}}-\mu_{g}\right)\left[\left(d^{2}+e^{2}\right) \gamma_{x_{-1}}+d e \gamma_{x}+e f\right] \\
\frac{\partial \mathcal{L}}{\partial \gamma_{x}}=-\mu_{\pi} d-\frac{\mu_{g} \beta d^{2}}{\kappa_{W}^{2} \kappa^{2}} \gamma_{x_{-1}}+\left(1+\frac{\mu_{g}}{\kappa_{W}^{2} \kappa^{2}}-\mu_{g}\right)\left(d^{2} \gamma_{x}+d e \gamma_{x_{-1}}+d f\right)
\end{gathered}
$$


The second-order conditions are

$$
\begin{gathered}
\frac{\partial^{2} \mathcal{L}}{\partial \gamma_{x-1}^{2}}=\frac{\mu_{g}}{\kappa_{W}^{2} \kappa^{2}}\left[(\beta d-e)^{2}+d^{2}\right]+\left(1-\mu_{g}\right)\left(d^{2}+e^{2}\right)>0 \\
\frac{\partial^{2} \mathcal{L}}{\partial \gamma_{x}^{2}}=\left(1+\frac{\mu_{g}}{\kappa_{W}^{2} \kappa^{2}}-\mu_{g}\right) d^{2}>0 \\
\frac{\partial^{2} \mathcal{L}}{\partial \gamma_{x_{-1}} \partial \gamma_{x}}=\frac{\mu_{g}}{\kappa_{W}^{2} \kappa^{2}}\left(d e-\beta d^{2}\right)+\left(1-\mu_{g}\right) d e \\
\frac{\partial^{2} \mathcal{L}}{\partial \gamma_{x}^{2}} \frac{\partial^{2} \mathcal{L}}{\partial \gamma_{x_{-1}}^{2}}-\left[\frac{\partial^{2} \mathcal{L}}{\partial \gamma_{x_{-1}} \partial \gamma_{x}}\right]^{2}=d^{4}\left[\left(1+\frac{\mu_{g}}{\kappa_{W}^{2} \kappa^{2}}-\mu_{g}\right)^{2}+\beta^{2}\left(1-\mu_{g}\right) \frac{\mu_{g}}{\kappa_{W}^{2} \kappa^{2}}\right]>0
\end{gathered}
$$

From (A.23), the conditions for the existence of a unique minimum are fulfilled.

\section{Proof of Proposition 6}

Introducing the rule(34) into goods demand equation (T1.1) results in the firstorder difference equation $(A .24)$ :

$$
g_{t+1 \mid t}=\left(1+\frac{\gamma_{g}}{\sigma \bar{\ell}_{C}}\right) g_{t}
$$

Equation $(A .24)$ implies $g_{t}=0$ for $\gamma_{g}>0$.

With sticky prices and wages, all versions of the model include equations (T1.2) through (T1.7). With stabilization of the output gap or price inflation or wage inflation, all the remaining variables can be expressed in terms of $\zeta_{t}$ and the three shocks $u_{t}, x_{t}$, and $z_{t}$. In each of these cases, equations (T1.2) through (T1.7) can be reduced to a second-order difference equation in $\zeta_{t}$ and the shocks.

With output-gap stabilization, the difference equation is

$$
\beta \zeta_{t+1}-\left(1+\beta+\kappa_{W}+\kappa_{P}\right) \zeta_{t}+\zeta_{t-1}+\left(\kappa_{W}+\kappa_{P}\right)\left(k_{u} u_{t}+k_{x} x_{t}+k_{z} z_{t}\right)=0
$$

Expressions for the $k_{j}$ are given in the text. The roots of equation $(A .25)$ are

$$
\tau_{1}, \tau_{2}=1+\frac{1-\beta}{2 \beta}+\frac{\kappa_{W}+\kappa_{P}}{2 \beta} \pm \sqrt{\left(1+\frac{1-\beta}{2 \beta}+\frac{\kappa_{W}+\kappa_{P}}{2 \beta}\right)^{2}-\frac{1}{\beta}}
$$

where the + and - of \pm apply to $\tau_{1}$ and $\tau_{2}$, respectively. Since $0<\beta<1$ and

$$
\begin{gathered}
\left(1+\frac{1-\beta}{2 \beta}+\frac{\kappa_{W}+\kappa_{P}}{2 \beta}\right)^{2}>\left(1+\frac{1-\beta}{2 \beta}+\frac{\kappa_{W}+\kappa_{P}}{2 \beta}\right)^{2}-\frac{1}{\beta} \\
=\left(\frac{1-\beta}{2 \beta}+\frac{\kappa_{W}+\kappa_{P}}{2 \beta}\right)^{2}+1+\frac{(\beta+1)\left(\kappa_{W}+\kappa_{P}\right)}{\beta}>\left(\frac{1-\beta}{2 \beta}+\frac{\kappa_{W}+\kappa_{P}}{2 \beta}\right)^{2}
\end{gathered}
$$

both roots are real and $0<\tau_{1}<1<\tau_{2}$. Since equation $(A .25)$ contains a lagged value, this root pattern implies determinacy.

The coefficients of the solutions for $\zeta_{t}$ and $\pi_{t}$ are displayed in the text. In deriving the variances of these variables, it is assumed that the three shocks $\left(u_{t}, x_{t}\right.$, and $\left.z_{t}\right)$ are mutually uncorrelated. Therefore, for $u_{t}, \mathcal{E} \zeta_{t-1} u_{t}=\rho_{u} \mathcal{E} \zeta_{t-1} u_{t-1}=\rho_{u} a_{0} \mathcal{E} \zeta_{t-2} u_{t-1}+$ 
$\rho_{u} a_{u} \sigma_{u}^{2}$, and by stationary $\mathcal{E} \zeta_{t-1} u_{t}=\frac{\rho_{u} a_{u} \sigma_{u}^{2}}{1-\rho_{x} a_{0}}$ and $\mathcal{E} \zeta_{t} u_{t}=\frac{a_{u} \sigma_{u}^{2}}{1-\rho_{x} a_{0}}$. Analogous relationships hold for $x_{t}$ and $z_{t}$.

\section{Proof of Proposition 7}

Introducing the rule (36) into goods demand equation (T1.1) results in the firstorder difference equation $(A .28)$ :

$$
\pi_{t+1 \mid t}=\gamma_{\pi} \pi_{t}
$$

Equation (A.28) implies $\pi_{t}=0$ for $\gamma_{\pi}>1$. As explained in the proof of Proposition 6 , with inflation stabilization the rest of the model is equations $(T 1.2)$ through $(T 1.7)$ which can be reduced to a second-order difference equation in $\zeta_{t}$ and the shocks:

$$
\beta \zeta_{t+1}-\left(1+\beta+\frac{\kappa_{W} \Delta}{\alpha}\right) \zeta_{t}+\zeta_{t-1}+\kappa_{W}\left(h_{u} u_{t}+h_{x} x_{t}+h_{z} z_{t}\right)=0 .
$$

Expressions for the $h_{j}$ are given in the text. The roots of equation $(A .29)$ are

$$
\tau_{1}, \tau_{2}=1+\frac{1-\beta}{2 \beta}+\frac{\kappa_{W} \Delta}{2 \alpha \beta} \pm \sqrt{\left(1+\frac{1-\beta}{2 \beta}+\frac{\kappa_{W} \Delta}{2 \alpha \beta}\right)^{2}-\frac{1}{\beta}}
$$

where the + and - of \pm apply to $\tau_{1}$ and $\tau_{2}$, respectively. The demonstration that both root are real and that $0<\tau_{1}<1<\tau_{2}$ is the same as the analogous demonstration in the proof of Proposition 6 except that $\frac{\kappa_{W} \Delta}{\alpha \beta}$ replaces $\frac{\kappa_{W}+\kappa_{P}}{2 \beta}$ everywhere. Since equation (A.29) contains a lagged value, this root pattern implies determinacy.

The statements in the last paragraph of the proof of Proposition 6 apply with appropriate modification.

\section{Proof of Proposition 8}

Introducing the rule (38) into goods demand equation (T1.1) results in the firstorder difference equation $(A .31)$ :

$$
\omega_{t+1 \mid t}=\gamma_{\omega} \omega_{t}
$$

Equation $(A .31)$ implies $\omega_{t}=0$ for $\gamma_{\omega}>1$. As explained in the proof of Proposition 6 , with inflation stabilization the rest of the model is equations $(T 1.2)$ through $(T 1.7)$ which can be reduced to a second-order difference equation in $\zeta_{t}$ and the shocks:

$$
\beta \zeta_{t+1}-\left(1+\beta+\frac{\kappa_{P} \Delta}{\Delta-\alpha}\right) \zeta_{t}+\zeta_{t-1}+\kappa_{P}\left(d_{u} u_{t}+d_{x} x_{t}+d_{z} z_{t}\right)=0
$$

Expressions for the $d_{j}$ are given in the text. The roots of equation $(A .32)$ are

$$
\tau_{1}, \tau_{2}=1+\frac{1-\beta}{2 \beta}+\frac{\kappa_{P} \Delta}{2 \beta(\Delta-\alpha)} \pm \sqrt{\left(1+\frac{1-\beta}{2 \beta}+\frac{\kappa_{P} \Delta}{2 \beta(\Delta-\alpha)}\right)^{2}-\frac{1}{\beta}}
$$

where the + and - of \pm apply to $\tau_{1}$ and $\tau_{2}$, respectively. The demonstration that both root are real and that $0<\tau_{1}<1<\tau_{2}$ is the same as the analogous demonstration in the proof of Proposition 6 except that $\frac{\kappa_{W} \Delta}{\alpha \beta}$ replaces $\frac{\kappa_{P} \Delta}{\beta(\Delta-\alpha)}$ everywhere 
because $\Delta-\alpha=\chi \bar{\ell}_{L}+(1-\alpha) \sigma \bar{\ell}_{C}>0$. Since equation $(A .32)$ contains a lagged value, this root pattern implies determinacy.

The statements in the last paragraph of the proof of Proposition 6 apply with appropriate modification. 


\section{Appendix B}

In this appendix we derive a logarithmic approximation for the first-order condition for the nominal wage which we call the wage setting equation. We repeat the first-order condition, equation (9) for convenience:

$$
W_{h, t} \mathcal{E}_{t} \sum_{s=t}^{\infty}\left(\xi_{W} \beta\right)^{s-t} \mathcal{U}_{1 ; h, s} \frac{\Pi^{s-t}}{P_{s}} L_{h, s}=\frac{1}{\theta_{W}} \mathcal{E}_{t} \sum_{s=t}^{\infty}\left(\xi_{W} \beta\right)^{s-t} \mathcal{U}_{3 ; h, s} L_{h, s} .
$$

Multiplying and dividing the left hand side of equation (B.1) by $W_{t}$ yields

$$
\mathcal{E}_{t} A_{t}^{W} \sum_{s=t}^{\infty}\left(\xi_{W} \beta\right)^{s-t} \mathcal{U}_{1 ; h, s} D_{t, s}^{W, P} L_{h, s}=\frac{1}{\theta_{W}} \mathcal{E}_{t} \sum_{s=t}^{\infty}\left(\xi_{W} \beta\right)^{s-t} \mathcal{U}_{3 ; h, s} L_{h, s}
$$

where

$$
A_{t}^{W}=\frac{W_{h, t}}{W_{t}}, D_{t, s}^{W, P}=\frac{W_{t} \Pi^{s}}{P_{s}}, \bar{A}^{W}=\bar{D}^{W}=1 .
$$

The expression for $L_{h, s}$ in equation (T1.4) can be rewritten as

$$
L_{h, s}=\left(D_{t, s}^{W}\right)^{\frac{1}{\theta^{-1}}} L_{s}, \quad D_{t, s}^{W}=\frac{W_{t} \Pi^{s}}{W_{s}} .
$$

Substituting the $\log$ differentials of $\mathcal{U}_{1 ; h, s}, \mathcal{U}_{3 ; h, s}$, and $L_{h, s}$ into the log differential of equation (B.2); recognizing that each term in the resulting equation is multiplied by either $\overline{\mathcal{U}}_{1 ; h, s} \bar{D}^{W, P} \bar{L}_{h}$ or $\frac{\overline{\mathcal{U}}_{3 ; h, s} \bar{L}_{h}}{\theta_{W}}$, which are equal; and rearranging yields

$$
\begin{aligned}
& \left(1-\xi_{W} \beta\right)^{-1}\left(1-\chi \bar{\ell}_{L} \epsilon_{L, W}\right) \hat{A}_{t}^{W}=-\mathcal{E}_{t} \sum_{s=t}^{\infty}\left(\xi_{W} \beta\right)^{s-t} \hat{D}_{t, s}^{W, P} \\
& +\mathcal{E}_{t} \sum_{s=t}^{\infty}\left(\xi_{W} \beta\right)^{s-t} \chi \bar{\ell}_{L} \epsilon_{L, W} \hat{D}_{t, s}^{W}-\mathcal{E}_{t} \sum_{s=t}^{\infty}\left(\xi_{W} \beta\right)^{s-t} \widehat{\mathcal{U}}_{1 ; h} \\
& +\mathcal{E}_{t} \sum_{s=t}^{\infty}\left(\xi_{W} \beta\right)^{s-t} \chi \bar{\ell}_{L} \hat{L}_{s}+\mathcal{E}_{t} \sum_{s=t}^{\infty}\left(\xi_{W} \beta\right)^{s-t} \chi \bar{\ell}_{Z} \hat{Z}_{s}
\end{aligned}
$$

where $\bar{\ell}_{C}, \bar{\ell}_{U}, \bar{\ell}_{L}$, and $\bar{\ell}_{Z}$ are defined in Table 3 .

Adding and subtracting $\xi_{W} \beta \chi \bar{\ell}_{L} \epsilon_{L, W} \mathcal{E}_{t}\left(\hat{W}_{t+1}-\hat{W}_{t}\right)$, noting that $\mathcal{E}_{t} \hat{D}_{t, t}^{W}=0$, making use of the definition of $\hat{A}_{t}^{W}$, recognizing that $\hat{C}_{h, t}=\hat{C}_{t}$ because of perfect insurance markets and that $\hat{U}_{h, t}=\hat{U}_{t}$ because of identical consumers yields

$$
\begin{aligned}
& \left(1-\xi_{W} \beta\right)^{-1}\left(1-\chi \bar{\ell}_{L} \epsilon_{L, W}\right) \hat{A}_{t}^{W} \\
= & \mathcal{E}_{t} \xi_{W} \beta\left(1-\xi_{W} \beta\right)^{-1}\left(1-\chi \bar{\ell}_{L} \epsilon_{L, W}\right) \hat{A}_{t+1}^{W} \\
& +\xi_{W} \beta\left(1-\xi_{W} \beta\right)^{-1}\left(1-\chi \bar{\ell}_{L} \epsilon_{L, W}\right) \mathcal{E}_{t}\left(\hat{W}_{t+1}-\hat{W}_{t}\right) \\
& -\left(\hat{W}_{t}-\hat{P}_{t}\right)+\sigma \hat{C}_{t}-\sigma \hat{U}_{t}+\chi \bar{\ell}_{L} \hat{L}_{t}+\chi \bar{\ell}_{Z} \hat{Z}_{t} .
\end{aligned}
$$

It can shown that

$$
\hat{A}_{t}^{W}=\frac{\xi_{W}}{1-\xi_{W}}\left(\hat{W}_{t}-\hat{W}_{t-1}\right)=\frac{\xi_{W}}{1-\xi_{W}} \omega_{t}
$$


Letting $\hat{W}_{t}-\hat{W}_{t-1}=\omega_{t}$ and $\hat{W}_{t}-\hat{P}_{t}=\zeta_{t}$ yields the log approximation to the wage setting equation

$$
\omega_{s}=\beta \omega_{t+1 \mid t}+\frac{\left(1-\xi_{W} \beta\right)\left(1-\xi_{W}\right)}{\left(1-\chi \bar{\ell}_{L} \epsilon_{L, W}\right) \xi_{W}}\left(\zeta_{t}^{s}-\zeta_{t}\right)=\beta \omega_{t+1 \mid t}+\kappa_{W}\left(\zeta_{t}^{s}-\zeta_{t}\right),
$$

where

$$
\zeta_{t}^{s}=\left(\hat{W}_{t}-\hat{P}_{t}\right)^{s}=\sigma \hat{C}_{t}-\sigma \hat{U}_{t}+\chi \bar{\ell}_{L} \hat{L}_{t}+\chi \bar{\ell}_{Z} \hat{Z}_{t} .
$$

is the (logarithmic deviation of the) supply real wage, the value of $\zeta_{t}$ that would result if wages were completely flexible $\left(\xi_{W} \rightarrow 0\right)$. 


\section{References}

Anderson, G. S., and G. Moore (1985) "A Linear Algebraic Procedure for Solving Linear Perfect Foresight Models", Economic Letters, 17, 247-52.

Benhabib, J., S. Schmitt-Grohe, and M. Uribe (1998) "Monetary Policy and Multiple Equilibria", Finance and Economics Discusion Series 1998-29, Federal Reserve Board.

Blanchard, O. (1997) "Comment", in NBER Macroeconomics Annual 1997, MIT Press, 289-295.

Blanchard, O., and C. M. Kahn (1980) "The Solution of Linear Difference Models under Rational Expectations", Econometrica, 48, 1305-11.

Bryant, R., P. Hooper, and C. Mann (1993) Evaluating Policy Regimes: New Research in Empirical Macroeconomics, Brookings Institution, Washington, D.C.

Calvo, G. (1983) "Staggered Prices in a Utility Maximizing Framework", Journal of Monetary Economics, 12, 383-398.

Clarida, R., J. Gali, and M. Gertler (1997) "Monetary Policy Rules and Macroeconomic Stability: Evidence and Some Theory", processed, New York University.

Dixit, A. K., and J. Stiglitz (1977) "Monopolistic Competition and Optimum Product Diversity", American Economic Review, 67, 297-308.

Erceg, C. J. (1997) "Nominal Wage Rigidities and the Propagation of Monetary Distrubances", International Finance Discussion Papers, No. 590, Federal Reserve Board.

Goodfriend, M., and R. King (1997) "The New Neoclassical Synthesis and the Role of Monetary Policy", in NBER Macroeconomics Annual 1997, MIT Press, Cambridge, 233-283.

Henderson, D., and W. McKibbin (1993) "An Assessment of Some Basic Monetary Policy Regime Pairs: Analytical and Simulation Results from Simple Multiregion Macroeconomic Models", in R. Bryant, P. Hooper, and C. Mann (eds.) Evaluating Policy Regimes: New Research in Empirical Macroeconomics, The Brookings Institution, Washington, D.C.

Henderson, D. W., and J. Kim (1998) "The Choice of a Monetary Policy Reaction Function in a Simple Optimizing Model", in A. Leijonhufvud (ed.) Monetary Theory as a Basis for Monetary Policy, Macmillan, London.

Kiley, M. T. (1998) "Monetary Policy under Neoclassical and New-Keynesian Phillips Curves, with an Application to Price Level and Inflation Targeting", Finance and Economics Discussion Series No. 1998-27, Federal Reserve Board. 
Kim, J. (1997) "Monetary Policy in a Stochastic Equilibrium Model with Real and Nominal Rigidities", processed, Board of Governors of the Federal Reserve System.

King, R. G., and A. L. Wolman (1998) "What Should the Monetary Authority Do When Prices Are Sticky?", in J. Taylor (ed.) Monetary Policy Rules, The University of Chicago Press, Chicago, forthcoming.

Kollmann, R. (1997) "The Exchange Rate in a Dynamic-Optimizing Current Account Model with Nominal Rigidities: A Quantitative Investigation", Working Paper, International Monetary Fund.

Leeper, E. (1991) "Equilibria under 'Active' and 'Passive' Monetary Policies", Journal of Monetary Economics, 27, 129-147.

Levin, A. (1989) "The Theoretical and Empirical Relevance of Staggered Wage Contract Models", Ph.D. dissertation, Stanford University.

Levin, A., V. Wieland, and J. C. Williams (1998) "Robustness of Simple Monetary Policy Rules under Model Uncertainty", in J. Taylor (ed.) Monetary Policy Rules, The University of Chicago Press, Chicago, forthcoming.

Phelps, E. S., and J. B. Taylor (1977) "Stabilizing Powers of Monetary Policy under Rational Expectations", Journal of Political Economy, 85, 163190.

Quandt, R. (1987) "Bibliography on Disequilibrium", mimeo, Princeton University.

Rotemberg, J., and M. Woodford (1998) "Interest-Rate Rules in an Estimated Sticky Price Model", in J. Taylor (ed.) Monetary Policy Rules, The University of Chicago Press, Chicago, forthcoming.

Rotemberg, J. J., and M. Woodford (1997) "An Optimization-Based Econometric Framework for the Evaluation of Monetary Policy", in NBER Macroeconomics Annual 1997, MIT Press, Cambridge, 297-346.

Rudebusch, G. D., and L. E. O. Svensson (1998) "Policy Rules for Inflation Targeting", in J. Taylor (ed.) Monetary Policy Rules, The University of Chicago Press, Chicago.

Schmitt-Grohe, S., and M. Uribe (1998) "Price-Level Determinacy and Monetary Policy under a Balanced Budget Requirement", processed, Federal Reserve Board.

Sims, C. A. (1994) "A Simple Model for Study of the Determination of the Price Level and the Interaction of Monetary and Fiscal Policy", Economic Theory, 4, $381-99$.

Taylor, J. (1979) "Staggered Contracts in a Macro Model", American Economic Review, 69, 108-113.

Taylor, J. (1980) "Aggregate Dynamics and Staggered Contracts", Journal of Political Economy, 88, 1-24. 
Tetlow, R., and P. von zur Muehlen (1996) "Monetary Policy Rules in a Small Forward-Looking Maco Model", processed, Federal Reserve Board.

Williams, J. C. (1997) "Simple Rules for Monetary Policy", processed, Federal Reserve Board.

Woodford, M. (1994) "Monetary Policy and Price Level Determinacy in a Cash-inAdvance Economny", Economic Theory, 4, 345-380.

Woodford, M. (1995) "Price-Level Determinacy without Control of a Monetary Aggregate", Carnegie Rochester Series on Public Policy, 43, 1-46.

Woodford, M. (1996) "Control of the Public Debt: A Requirement for Price Stability?", NBER Working Paper 5684, National Bureau of Economic Research.

Yun, T. (1996) "Nominal Price Rigidity, Money Supply Endogeneity, and Business Cycles", Journal of Monetary Economics, 37, 345-370. 


\section{Figure 1: Sticky Prices and Flexible Wages}

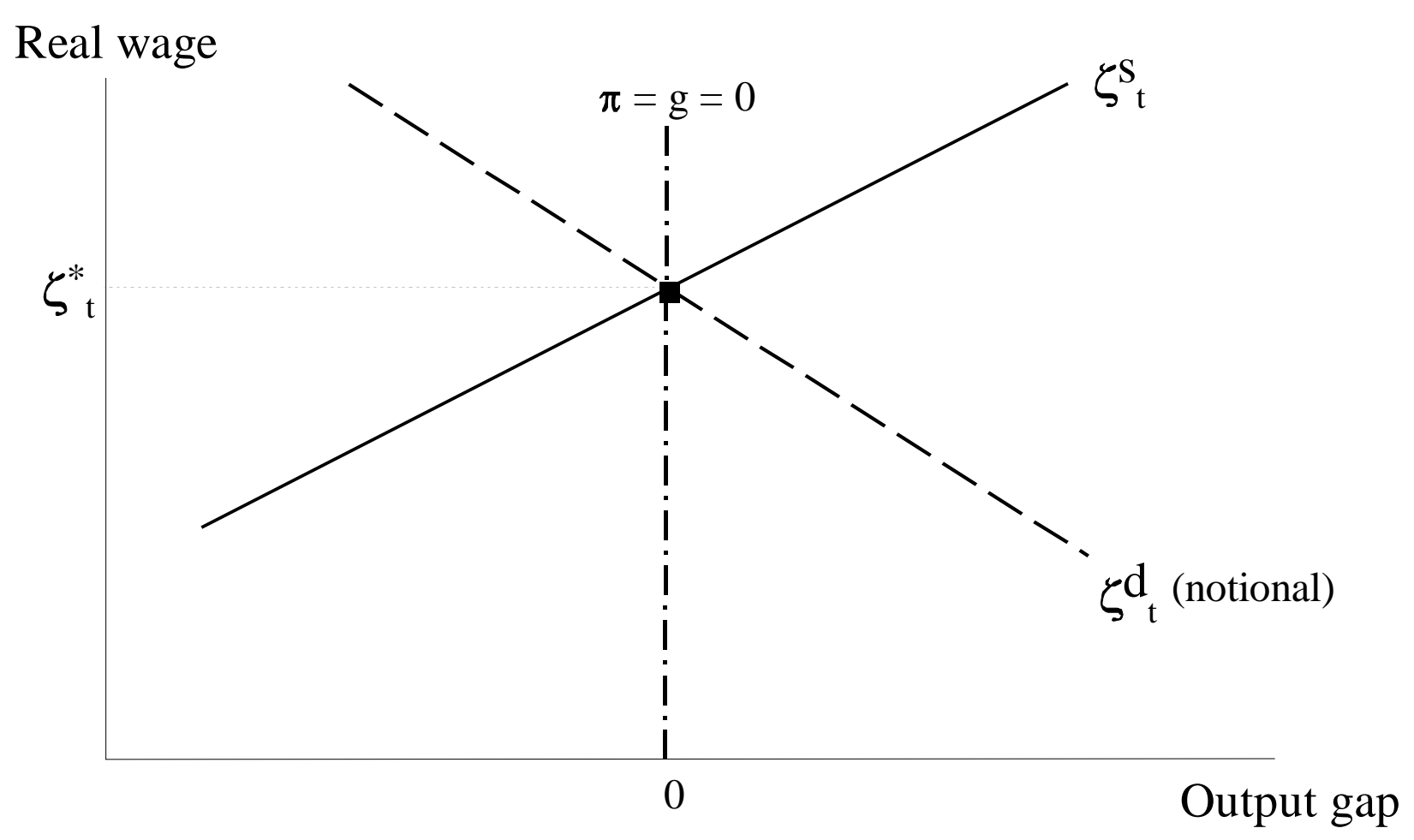

Figure 2: Sticky Wages and Flexible Prices

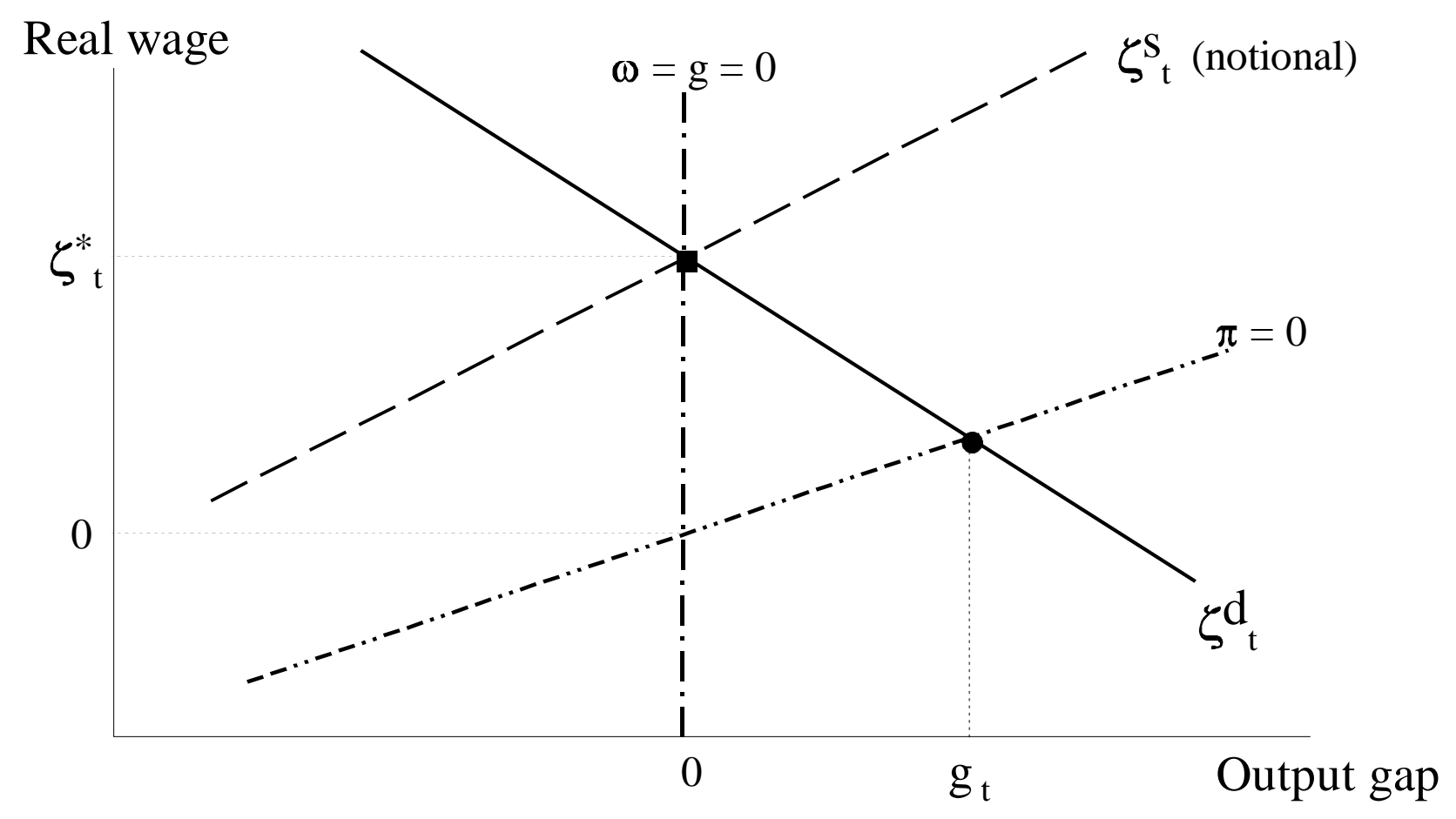




\section{Figure 3}

Variance Tradeoffs under Sticky Wages and Flexible Prices $(\alpha=0)$

Average contract duration $=1.1$ quarters
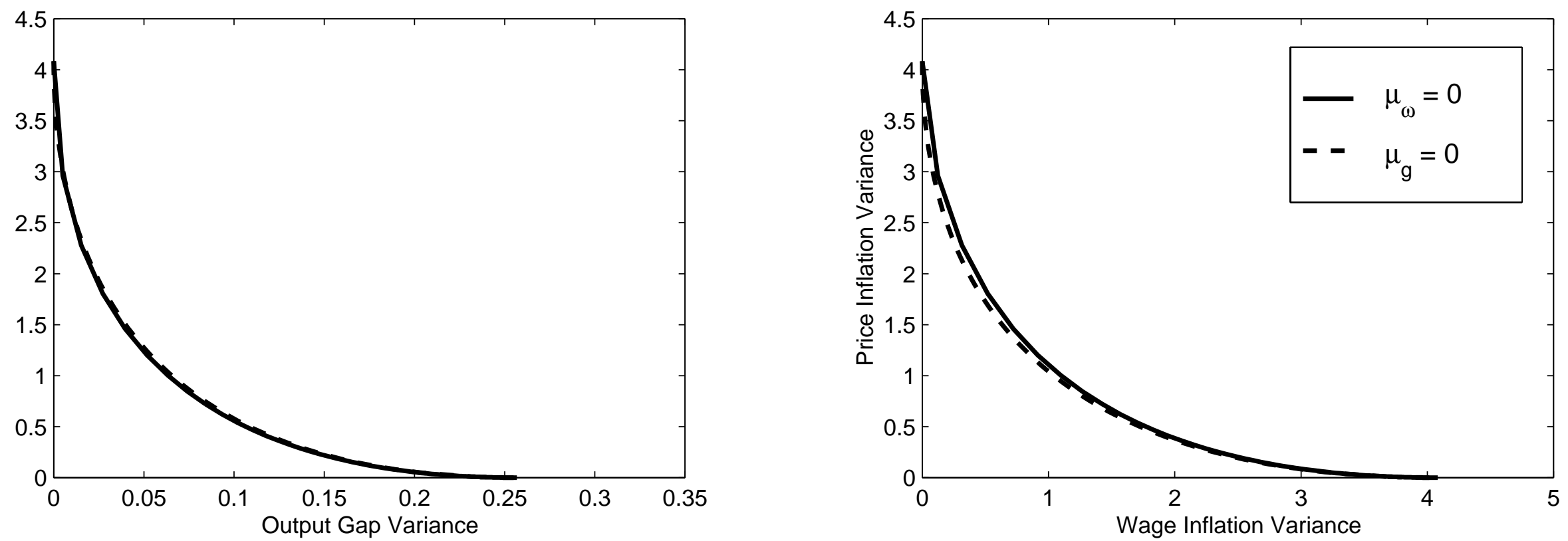

Average contract duration $\mathbf{=} 2$ quarters
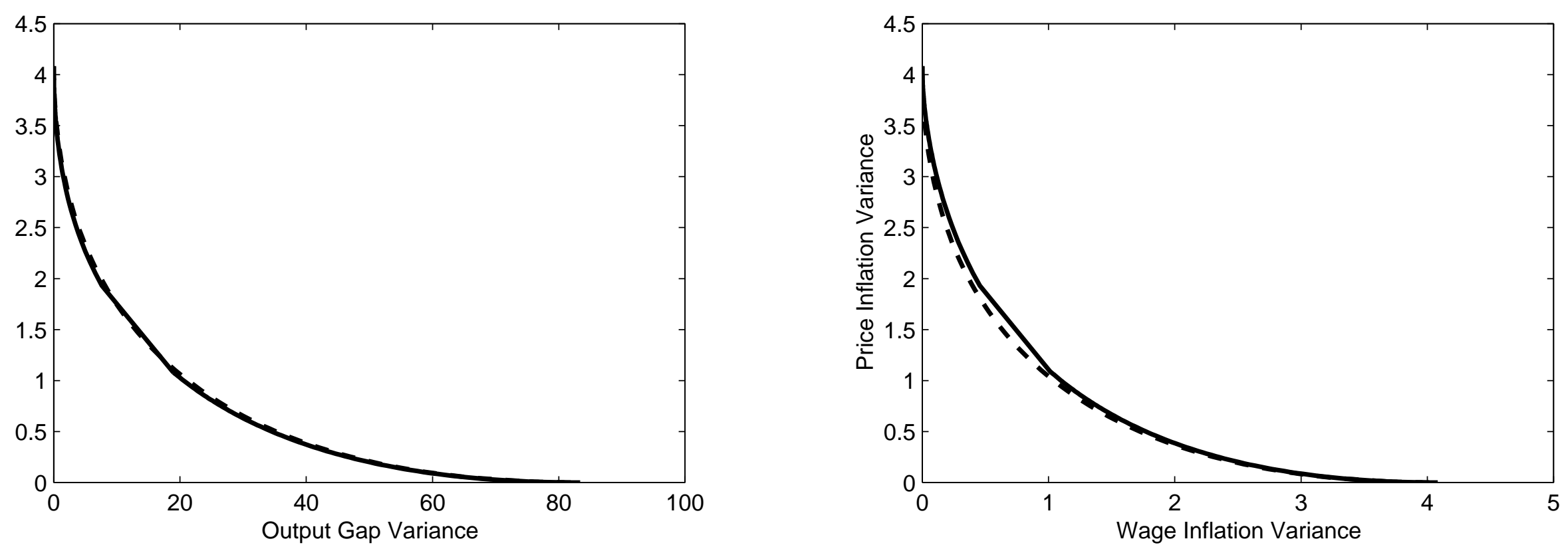
Figure 4:

Incomplete Stabilization Rules

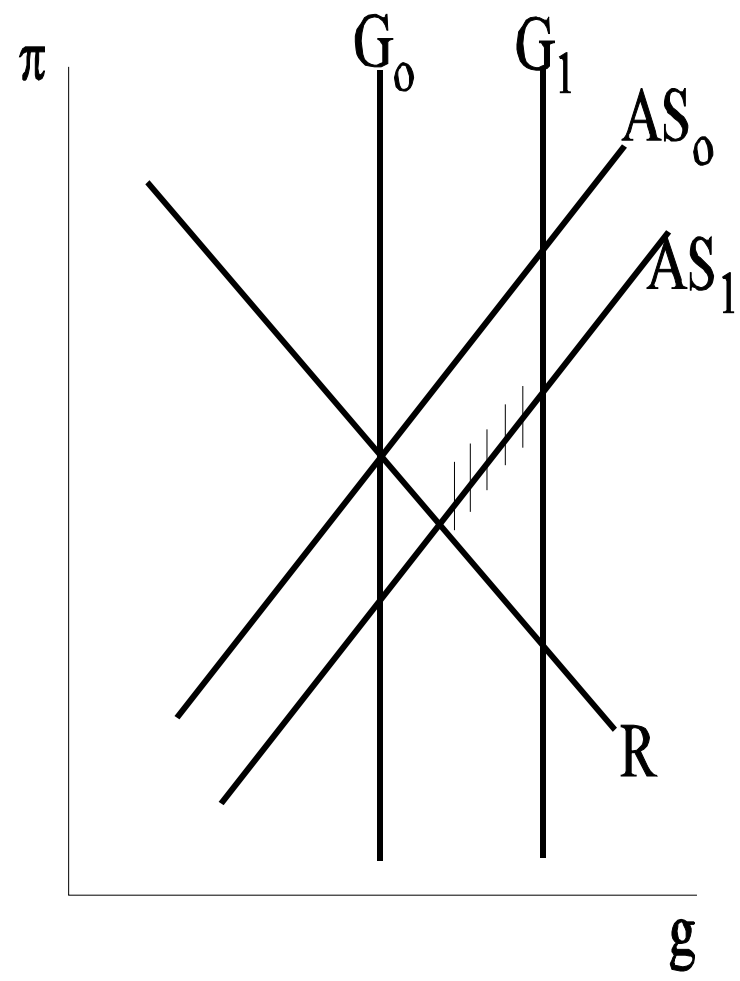

Figure 5:

Equilibration Process

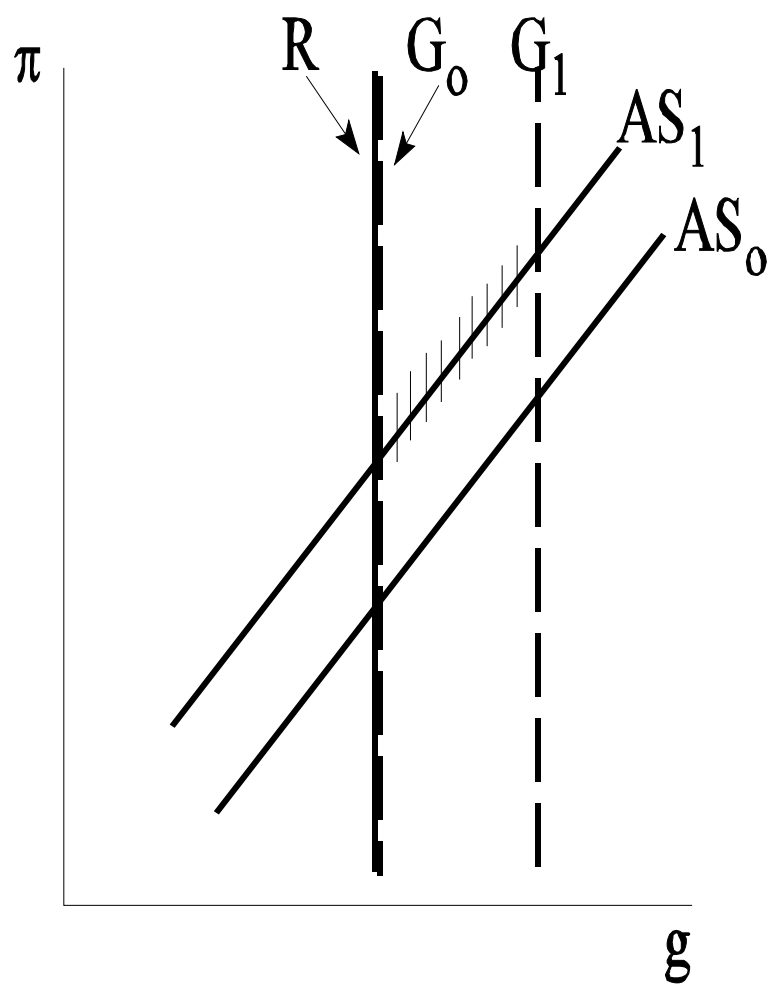

Figure 6: Complete Stabilization Rules

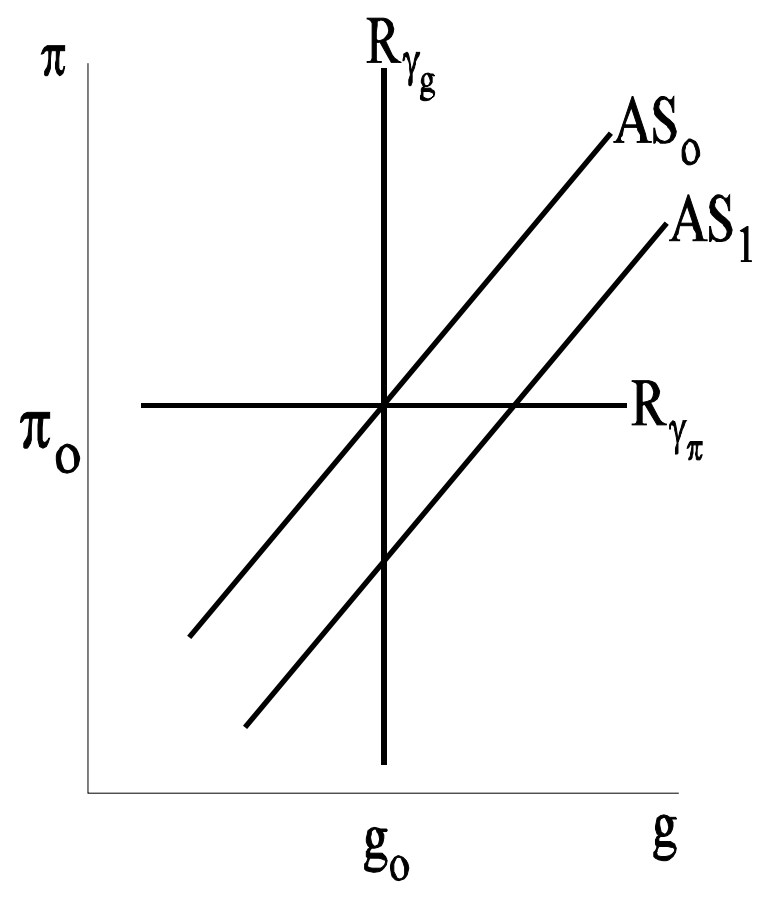


Figure 7

Variance Tradeoffs under Sticky Wages and Sticky Prices

Productivity Shocks (Three 2-dimensional Views)
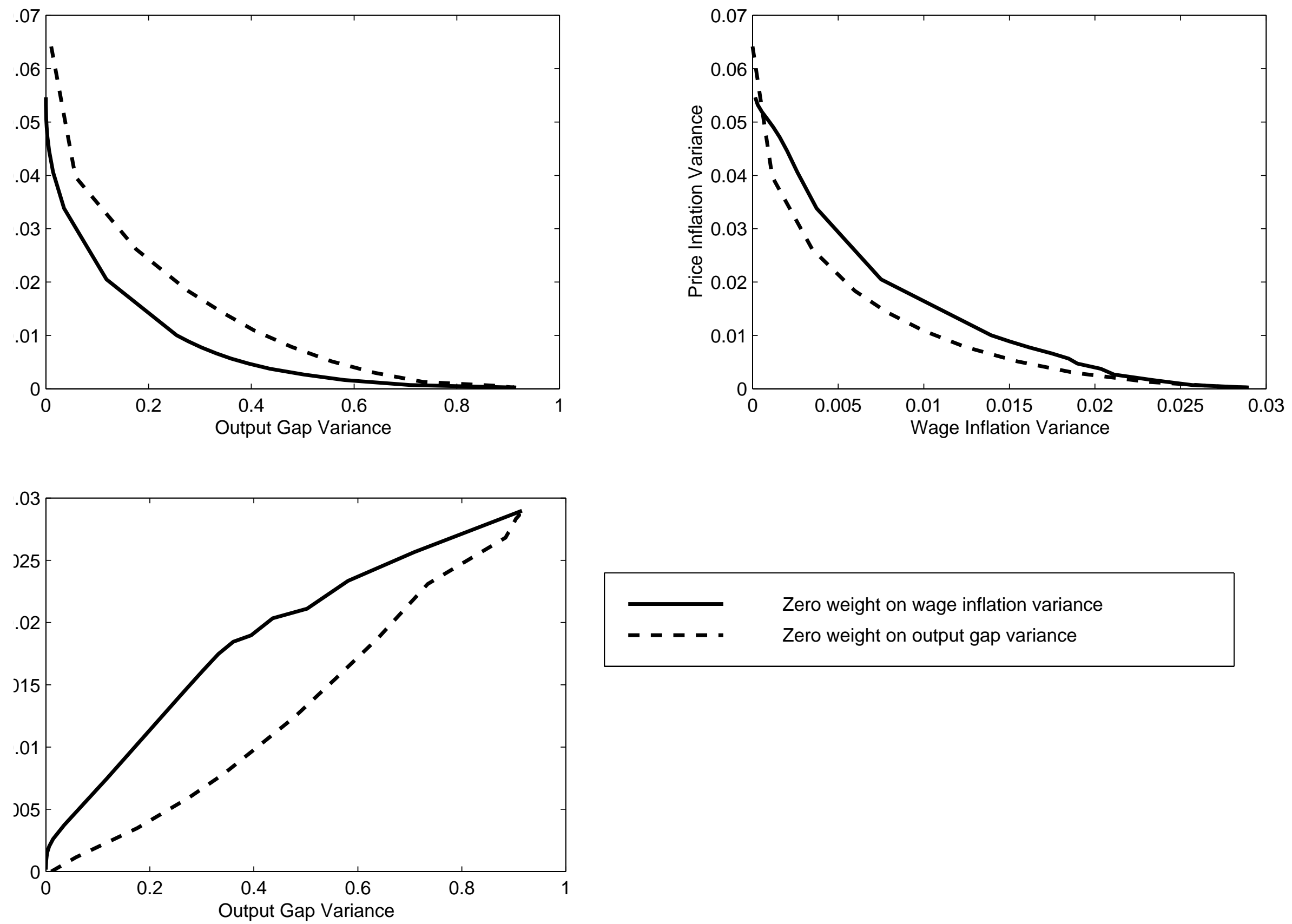

Z Zero weight on wage inflation variance

- _ - . - Zero weight on output gap variance 
Figure 8

Variance Tradeoffs under Sticky Wages and Sticky Prices

Consumption Demand Shocks
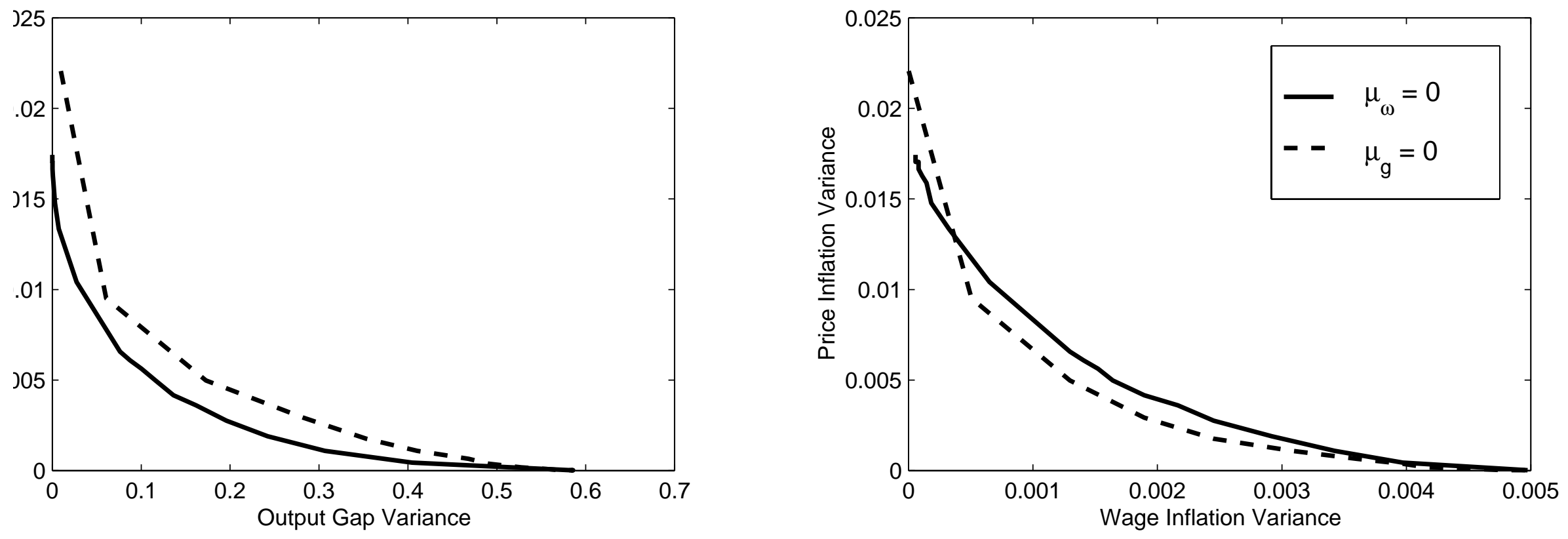

Labor Supply Shocks
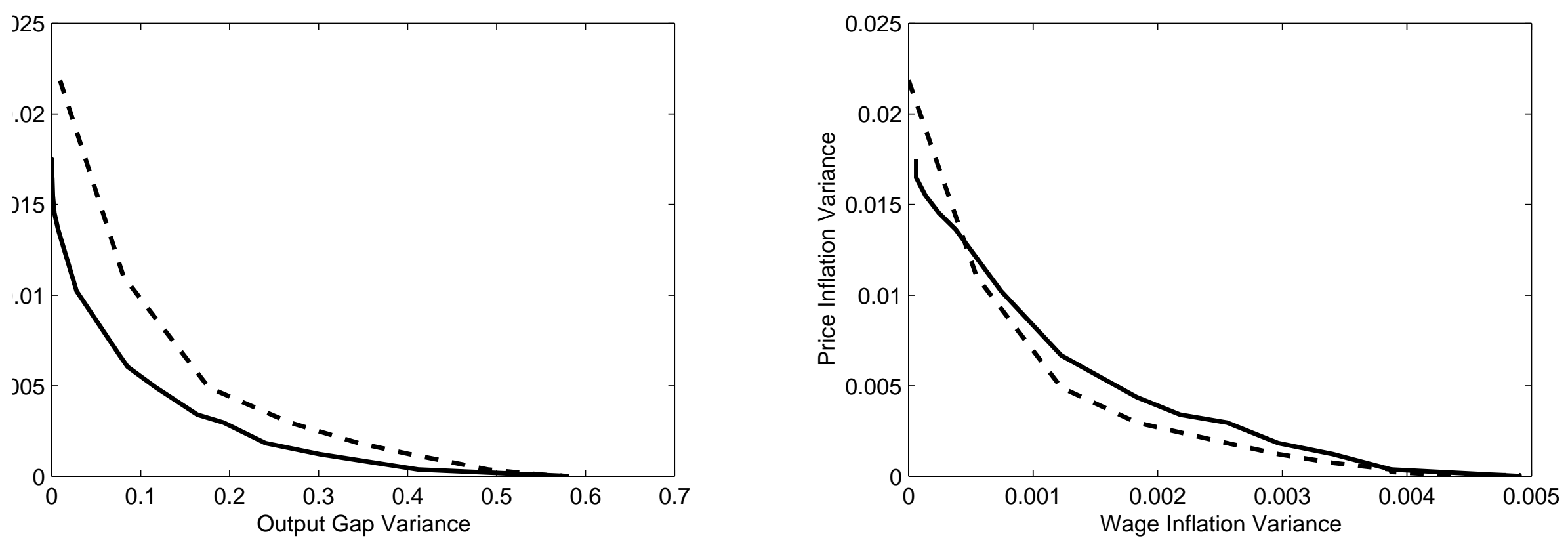